Carleton University

The Political Economy of Chronicity and Primary Health Care in Ontario

\author{
A thesis submitted to the Faculty of Graduate Studies and Research in partial fulfillment \\ of the requirements for the degree of Master of Arts
}

School of Canadian Studies

By

\title{
Michael Bell
}

Ottawa, Ontario

August 2008

(C) 


$\begin{array}{ll}\begin{array}{l}\text { Library and } \\ \text { Archives Canada }\end{array} & \begin{array}{l}\text { Bibliothèque et } \\ \text { Archives Canada }\end{array} \\ \begin{array}{l}\text { Published Heritage } \\ \text { Branch }\end{array} & \begin{array}{l}\text { Direction du } \\ \text { Patrimoine de l'édition }\end{array} \\ \begin{array}{l}\text { 395 Wellington Street } \\ \text { Ottawa ON K1A 0N4 } \\ \text { Canada }\end{array} & \begin{array}{l}\text { 395, rue Wellington } \\ \text { Ottawa ON K1A 0N4 } \\ \text { Canada }\end{array}\end{array}$

Your file Votre référence ISBN: 978-0-494-43445-1 Ourfile Notre référence ISBN: 978-0-494-43445-1

NOTICE:

The author has granted a nonexclusive license allowing Library and Archives Canada to reproduce, publish, archive, preserve, conserve, communicate to the public by telecommunication or on the Internet, loan, distribute and sell theses worldwide, for commercial or noncommercial purposes, in microform, paper, electronic and/or any other formats.

The author retains copyright ownership and moral rights in this thesis. Neither the thesis nor substantial extracts from it may be printed or otherwise reproduced without the author's permission.
AVIS:

L'auteur a accordé une licence non exclusive permettant à la Bibliothèque et Archives Canada de reproduire, publier, archiver, sauvegarder, conserver, transmettre au public par télécommunication ou par l'Internet, prêter, distribuer et vendre des thèses partout dans le monde, à des fins commerciales ou autres, sur support microforme, papier, électronique et/ou autres formats.

L'auteur conserve la propriété du droit d'auteur et des droits moraux qui protège cette thèse. $\mathrm{Ni}$ la thèse ni des extraits substantiels de celle-ci ne doivent être imprimés ou autrement reproduits sans son autorisation.
In compliance with the Canadian Privacy Act some supporting forms may have been removed from this thesis.

While these forms may be included in the document page count, their removal does not represent any loss of content from the thesis.
Conformément à la loi canadienne sur la protection de la vie privée, quelques formulaires secondaires ont été enlevés de cette thèse.

Bien que ces formulaires aient inclus dans la pagination, il n'y aura aucun contenu manquant.

\section{Canada}




\begin{abstract}
This thesis examines the intersection of primary health care reform, chronic health conditions and political economy, through the assessment of two existing delivery models. Two models of primary health care in Ontario are compared, specifically in terms of their ability to care for chronicity. This study highlights that care for chronic health conditions requires an approach that is inclusive of health promotion concepts, rather than the traditional medical model ideology. Particular attention is paid to how the competing interests and values of the stakeholders involved are represented in policy. Despite shortcomings with each model, in general the CHC model is better equipped to translate the values that are espoused in Canadian health policy documents and provide better care for people with chronic conditions.
\end{abstract}




\section{Acknowledgements}

It is a pleasure to thank the people who made this thesis possible. It has been a test of endurance, and like any long-term project there have been ups and downs. Since beginning this program, I have had three different jobs, lived in two homes, got married and had two children. School has been merely fraction of what has been going on, but through this experience I have grown considerably.

Thanks to Hugh Armstrong, my advisor, for his patient support, guidance and good nature throughout the process. Thanks also to Richard Nimijean, my second reader, for ongoing encouragement and direction. Between my course work and thesis, these two people were involved with most of what I did during my time as a graduate student at Carleton.

Thanks also to the School of Canadian Studies for their ongoing availability. As a part-time, long distance student this was important to me. Specifically, Mary Casaubon's positive, accommodating attitude has made every interaction a positive one.

To everyone I have worked with within the Community Health Centre model, your wisdom and insight has taught me a lot. I continue to be grateful for the opportunity to work in the very sector in which I study and write about, even despite the challenges posed by the concept of praxis.

Finally, most importantly, a huge thanks to my family - my wife Danielle, and daughters Reegan and Rachel. Time spent on this thesis was time away from them. Without a doubt, I would not have been able to complete the project without Danielle's support and encouragement. 


\section{Table of Contents}

Page

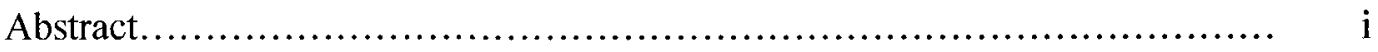

Acknowledgements...................................................... iii

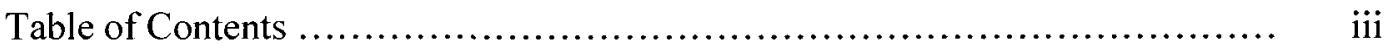

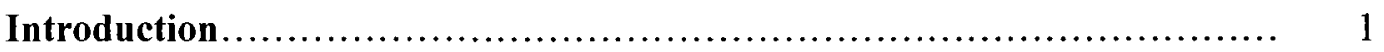

Chapter One: Political Economy Approach to Primary Health Care and Chronicity....

Magnitude of Chronicity.

Health, Medicine and Chronicity

Needs of people with chronic conditions

Primary Health Care and Primary Care.

Organizing Primary Health Care and Chronicity.

Current Primary Health Care Environment.

Conclusion.

Chapter Two: Values of Key Stakeholders.

Levels of Analysis.

Medical Dominance. ...

Policy Makers.

Public.

Conclusion.

Chapter Three: Theoretical Framework for Addressing Primary Health Care and Chronicity.

Framework Described

Community Action and Supportive Environment.

Teamwork

Reimbursement....

Access and Continuity

Governance.

Conclusion.

Chapter Four: $C H C$ and FHT: Assessing Care for Chronic Conditions

Teamwork

Reimbursement

Quality of Care.

Governance.

Conclusion. 


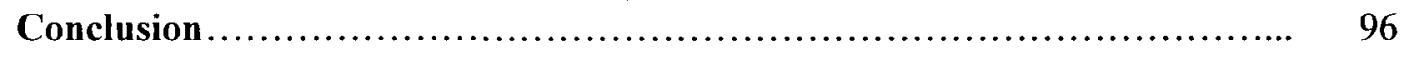

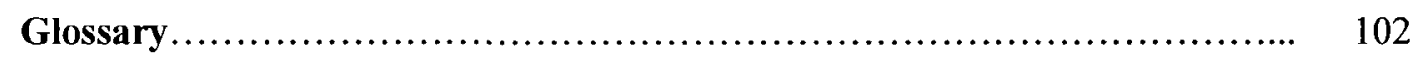

Appendices..................................................... 103

Bibliography..................................................... $\quad 118$ 


\section{Introduction}

Implementing primary healthcare reform is about fundamentally altering the way the entire healthcare system works, bringing changes in the balance between prevention and treatment, the training and scope of practice of providers, the modes of funding, the prevailing culture, and the balance of interests (Dubois, 2004, p. 4).

This is a study of Primary Health Care (PHC) reform in Ontario, in the context of caring for people with chronic health conditions. Of the many identified problems with the current healthcare system, two major problems stand out: first, the ongoing pursuit for general PHC reform (defined as a shift from physicians working as individuals to teams of multidisciplinary health care providers, " $24 / 7$ " access, and changing the way physicians are remunerated); and second, which is less identified, is changing the way chronic health conditions are perceived and cared for, specifically the need to provide more holistic, non-medical care strategies.

Attention is paid to two main delivery models of PHC in Ontario. The newer version is called the Family Health Team, and the more longstanding, the Community Health Centre. I chose to look at these models because, while other models exist, these two appear to be models 'of the future' in this province. In addition, each is pursuing primary healthcare reform objectives put forth by Ontario's Ministry of Health and Long Term Care in different ways, which may affect healthcare delivery for people with chronic conditions.

The changing needs of individuals with a chronic condition, or perhaps better articulation of longstanding needs, are also examined in this thesis. Chronic conditions are important because they affect one in three Ontarians and account for 89 percent of all deaths in Canada (Ontario Health Quality Council, 2008). Concepts that are normally isolated to other levels of health care, such as health promotion or population health (e.g., 
social determinants of health, self-management and empowerment, client engagement) are brought to the forefront because of convincing stories that acute, hospital based, cure oriented care is insufficient for the varied needs of chronicity.

My research question, "Is one model of primary health care (the Family Health Team or the Community Health Centre) better equipped to address the needs of people with chronic health conditions?" is best answered using a political economy perspective. Assessing the impact of the competing values and interests of the stakeholders involved explains how care for people with chronic health conditions could be organized.

I explore a number of sub-questions including:

1. What factors lead to or cause chronic conditions?

2. Why is the primary health care system in need of change?

3. What are the values of the key stakeholders?

4. How do the values presented in Canadian health policy documents surface in primary health care?

5. What are the major barriers to change/reform in primary health care?

6. Who benefits from the decisions that have been made?

These questions are important as they address the two main levels of analysis of the thesis. First, they enable a presentation of the importance of health promotion concepts in Primary Health Care; specifically the point that due to the long-term course of chronicity, non-medical determinants of health should be considered alongside the medical determinants in the care strategy for people with chronic health conditions. This highlights one level of needed change, from an acute cure perspective to a long-term holistic care perspective. Secondly, these questions address the competing values at stake in this debate, and how these values are translated into care delivery.

Despite a wealth of information on different models of PHC, most of the studies use similar theoretical perspectives which do not pay adequate attention to how PHC delivery 
models are designed to meet the changing chronicity needs of the population. This thesis addresses this gap in the literature.

As will be demonstrated, the process of PHC reform in Ontario exhibits tendencies that appear to support the status quo and frustrate efforts of certain groups to make progressive change. There are a number of theoretical frameworks for understanding the nature of PHC reform. These include sociological theories of professions (e.g., professional dominance of doctors over the division of labour in health care, clinical autonomy, etc.), power theory (seen as various forms of constraint on human action, but also that which makes action possible) and political economy of health (assessing conditions which shape population health and health service development within a wider economic and political context.) Though each body of theory has something to contribute, political economy offers the greatest potential to help explain the breadth of issues and their interrelation.

Canada has a rich history of political economy, including work from Leo Panitch, Wallace Clement, Rianne Mahon, and Pat and Hugh Armstrong to name a few. The theory, which once focused on class and industrialism, has evolved to now include more specific attention to power, agency, ideology and discourse. Yet the premise remains there is inequity in the way that economics influences politics.

Political economy is employed in this study in three ways. Firstly, political economy inherently acknowledges that there is conflict between economics and politics in a capitalist mode of production. A reliance on the free market advantages some groups while disadvantaging others. The belief that economic growth equates to improved population health is not supported in this thesis. 
Secondly, healthcare and healthcare systems are ever-changing. The role that different groups have played in these changes demonstrates the role of agency in addition to structure. For instance, the manner in which physician groups have blocked repeated calls for changes to primary health care delivery will be examined. Specifically this includes delaying, and attempting to re-construct, the introduction of multidisciplinary teams, as well as an unwillingness to accept alternative payment schemes. Both examples have been shown to improve health outcomes for people with chronicity, yet because they were perceived not to be in physicians' best interest, they have been challenged vigorously.

Thirdly, in assessing barriers to progressive change, specific attention must be paid to inequality and power. The subjective nature of the concepts 'primary health care' and 'chronicity' allow for different interpretations and different priorities by the different players involved. PHC, chronicity and politics are complex, multi-factorial and dependent on relationships to realize progressive change. Progress as used here requires all stakeholders to embrace a more holistic definition of health, and also embrace the need for more egalitarian relationships among healthcare provider groups and between providers and patients. Understanding the complexity requires a critical eye and acceptance of the central position of providers of healthcare, especially the medical profession (Flood, Tuhoy, $\&$ Stabile, 2004). The theory of chronicity could be considered the antithesis of the medical model. Because the medical model is based on issues like curing, standardizing and quantifying, it is at odds with the subjective, personal health needs of those with chronic conditions. Often left out of policy debates in this arena is the patient, because other stakeholders hold more power and influence. 
These ideological differences can result in different objectives and different policy outcomes, which in turn can affect the type of healthcare provided. The claim that nonmedical determinants of health (i.e., health promotion work), deserve much more : attention in a primary health care setting has not been accepted in the traditional (and powerful) medical model ideology, and as such systems have not changed. Furthermore, concepts such as access and continuity of care are defined differently by the different stakeholders. For example, powerful groups (physician groups and the state) continue to rely on 'bottom line' numbers to evaluate access. Much less attention is paid to the specific services Ontarians have access to. This assessment of the interests and values of the stakeholders involved highlights that in the end, the values of the people who matter most (in this case those people with a chronic health condition and in need of care) are trumped by the interests of more powerful players.

Political economy of health helps us understand important health policy issues. It informs my research question because it assesses the multi-factorial nature of both primary health care and chronicity and applies it to policy. It provides an assessment of the relationships between politics, economics, PHC reform and chronicity. I use a range of different linkages (e.g., the intersection of values of the state, physician groups, other health care providers and patients) to focus on the effects of a competitive struggle for economic and political advantage, where the prospects of some stakeholders are enhanced and others are diminished. Simply put, I assess the winners and losers. Political economy theory is used as a lens to evaluate efforts toward progressive change, specifically looking into PHC policy decisions and assessing who benefits and who loses. 
Current political economy does not address the intersection of chronicity and PHC reform. As such, this thesis contributes to the body of knowledge.

Using the two PHC models in question as an example of a policy choice, the framework is designed to examine the impact of this policy as it pertains to chronicity. Five criteria make up this framework, and each is operationalized through subcomponents.

The scope of this study is limited to PHC reform in the context of chronic health conditions, and hence refrains from other meaningful health care debates. Chronic care as it relates to secondary, tertiary and quaternary care will not be dealt with here. Issues such as the federal/provincial funding dilemma, regionalization (i.e., Local Health Integration Networks), privatization, hospital reform, pharmacare, or homecare will not be dealt with.

The geographical parameters of my study are contained to the province of Ontario. This research is timely because of the growing burden of chronicity and the ongoing focus on primary health care reform. Chronic health conditions are a focal point of this debate because they are such an urgent concern for primary health care, and affect so many Ontarians.

The timeline used for this study commences in the 1970s when a great deal of research began on this topic, and ends in 2007 . The intention is to examine the decisions that have been made and consider the implications of the changes.

The first two chapters are explanatory in nature, laying the foundation for future arguments and conclusions. Chapter One presents and compares the current medical model paradigm with the holistic definition of health in the context of the needs of those 
with chronic health conditions. It presents the importance of translating a broader concept of health into pertinent components of the healthcare system, such as primary healthcare, health promotion and population health. This provides the reader with a basis on which primary healthcare models will be critiqued in future chapters. Chapter Two identifies the needs and interests of the key parties involved, suggesting that policy development can be at the mercy of competing values and existing power relationships. Chapter Three presents and describes the framework methodology that will be used in the Chapter Four. This methodology was developed by merging and adapting pertinent elements from two existing frameworks, namely a PHC framework (developed by Barbara Starfield), and a chronicity framework (Ontario's Chronic Disease Prevention and Management framework.) Definitions and justification for each element of the framework are provided, highlighting their importance in the context of $\mathrm{PHC}$ and chronicity. Chapter Four evaluates the Family Health Team and Community Health Centre models, looking specifically at how each is able to attend to the needs of people with chronic health conditions. The conclusion summarizes the argument that despite issues within each model, in general the $\mathrm{CHC}$ model is better equipped to translate the values that are espoused in Canadian health policy documents and therefore provide better care for people with chronic conditions. This comes at a cost, however, as the model struggles to increase access and improve efficiency through better functioning multidisciplinary teams.

The clearest limitation of this study is the theoretical basis on which any conclusions are drawn. With no empirical data, conclusions are dangerous, particularly given the vast and varied characteristics of each model. Finally, the FHT model is still in its infancy, 
and drawing early conclusions may be premature. Despite these limitations, the study informs the general knowledge base by presenting an analysis not yet undertaken. Specifically, the examination of PHC reform and chronicity by means of a new political economy theoretical perspective does not exist in current literature. 


\section{Chapter One: A Political Economy Approach to PHC and Chronicity}

The intention of this chapter is to introduce concepts and issues that will be explored throughout the thesis. Three sections, examined using a political economy lens, will be reviewed. The first deals with the concept of chronicity; the magnitude, causes, and needs and values of people who deal with a chronic health condition. The second section explains why the distinction between primary care and primary health care (PHC) is important, while the third section ties together the PHC needs of those with chronicity.

The concepts of change and reform are a thread of the study. In this chapter, change is examined based on the needed shift from the traditional medical model paradigm of care toward a perspective that is better able to care for chronicity. As will be shown, the subjective nature of health and chronicity leaves much up to interpretation by the players involved. Reforming PHC to better address the needs of people with chronic conditions is dependent on how the terms and the problems are defined. However, traditional definitions and ideologies often prevent meaningful change in this area.

The root causes of chronicity have been linked to the root causes of ill-health in general. As such, a thorough understanding of different ways of perceiving health is critical to the basis of this thesis. As will be argued, this theoretical perspective is effective in considering the basis of health, where the whole is more than the sum of its parts. However, attention is first paid to the magnitude of chronicity in Ontario to illustrate why this topic is of importance. 


\section{Magnitude of Chronicity}

Globally, chronic health conditions are a growing concern because they are the leading causes of avoidable illness, health care system utilization, and premature deaths (Haydon et al., 2006). They are currently responsible for 60 percent of the disease burden globally, and this figure is expected to rise to 80 percent by the year 2020 (ibid). According to the World Health Organization (2005a, p.4), chronic conditions are defined as "health problems that require ongoing management over a period of years or decade, and include: diabetes, heart disease, asthma, chronic obstructive pulmonary disease (COPD), cancer, HIV/AIDS, depression and physical disabilities."

Canada is not immune to the effects of chronicity. Eighty-nine per cent of all deaths in Canada can be attributed to chronic disease (Patra et al., 2007). In Ontario, 80 percent of people over age 45 have a chronic disease, and almost 70 percent of those individuals are living with two or more chronic conditions (ibid). The clinical outcomes for people with chronic health conditions are less than ideal. Studies show that adherence to recommended care for chronic conditions ranged from 45 percent for diabetes to 68 percent for coronary artery disease (Morgan, Zamora, \& Hindamarsh, 2007).

Furthermore, chronic health conditions constitute the major cost demand on the health care system. According to Health Canada (2002), the total cost of illness, disability and death due to chronic disease is over $\$ 80$ billion annually. In Ontario, this represents 55 percent of the total health care costs (Hayward \& Colman, 2002). In terms of resource utilization, the top five percent of people with multiple chronic conditions account for 30 percent of health care expenditures (Haydon et al., 2006). More specifically, this 'top tier' accounts for 30 percent of physician payments, 36 percent of hospitalizations, and 
64 percent of total hospital days. Moreover, 80 percent of these people have at least six complex chronic conditions, requiring intensive management including a high degree of coordination among multiple providers and agencies, in addition to frequent contact, coaching and support (ibid).

These figures illustrate that outcomes for people with chronic conditions are unfavourable, and that the health care budget is consumed with the burden of chronicity. While awareness of this information is a fundamental step prior to considering potential solutions, a critical piece remains. To truly understand the issue, we must move beyond outcome-based quantitative figures and consider the root causes of chronic health conditions. Moreover, consideration for designing healthcare systems to best address the personal impact of a long-term chronic condition is critical.

\section{Health, Medicine and Chronicity}

Health is not a clear concept; a myriad of physical, emotional, spiritual, social and economic components, all infinitely complex, play a role in a person's health status. Health is difficult to interpret simply because of its subjective and personal nature. Therefore, care of a person's health is a complicated matter. Indeed, there is no accepted tool, specialty or score that provides a comprehensive health status.

Medicine, in some ways, is easier to comprehend. Medicine has been intimately linked to what is known as the medical model, a model that has provided a paradigm for interpreting illness. The medical model serves as a tool in dealing with the many subjectivities included in a person's health status, because of its ability to quantify, standardize and base practices on proven evidence. The medical model interprets health to mean 'the absence of disease or disability' (Larson, 1999). 
A more comprehensive definition of heath is put forth by the World Health Organization (WHO): "Health is a state of complete physical, mental, and social wellbeing and not merely the absence of disease or infirmity" (World Health Organization, 1948, p.2). While this definition is the most popular worldwide, many feel that it is too broad. For instance, as the medical sociologist James Larson $(1999$, p. 126) states, the WHO's "utopian definition of health makes invalids of us all. Ninety-nine percent of the world's population must be in need of care and attention." Such criticisms are understandable, as attending to this definition of health could consume the entire Canadian economy. Furthermore, as Robert Evans (1993) puts it, the WHO definition is difficult to use as the foundation of health policy, because implicitly it includes all policy as health policy.

Others believe that the WHO definition is incomplete. Bunton and Macdonald (1991), among others (e.g., Raeburn \& Rootman, 1999) have noted that while the WHO emphasizes wholeness, it is essentially weak because it fails to refer to the search for interaction and equilibrium with one's environment and community. Furthermore, cross cultural studies indicate that people's experiences of health can usefully be organized under the following categories: 1) feeling vital, full of energy 2) having good social relationships 3) experiencing a sense of control over one's life and one's living conditions 4) being able to do things one enjoys 5) having a sense of purpose in life and 6) experiencing a connectedness to 'community' (Labonte, 1997). This posits health in a very subjective (and an appropriately personal) light. The act of including subjectivities to 'health' does not imply that the term loses meaning. Rather, it frees the concept of health from the relationship to disease (ibid). 
This perspective is critical to the understanding of how care systems should be designed for chronicity. According to Peter Conrad (2005, p. 5):

Health is the person's experience; disease constitutes a bodily disorder as agreed upon by physicians. Some people do not experience illness when they have a diagnosed disease. Other people experience illness before receiving a diagnosis or being believed to have a disease. A chronic illness can be episodic or endless; it may have long plateaus or continual progression. It is at once subjective and social; it includes experiencing inchoate emotions and bodily sensations as well as making such experiences meaningful and responding to imagined or actual social responses.

According to Larson (1999), the medical model definition is the most widely used conceptualization in health research. The use of this narrow vision is helpful in research and acute settings, where intimate knowledge of the patient's make up or history is not critical. Despite its critics, and the more elaborate definitions, most health policy is still based on the medical model. In many cases, the use of ideology has been to the detriment to those living with a chronic health condition. Reconciling the two related but distinct fields has been consumed by debate over the years. This thesis adds to that debate in its own way. Looking specifically at the needs of people with chronic health conditions, I set out to assess if one model of health care delivery is better than another.

\section{Needs of people with chronic health conditions}

Regardless of age at onset, whether the causes of the condition are physical or due to other factors, essentially all chronic conditions present a common set of challenges. These challenges apply not only to the person diagnosed, but also to their families and even the community in which they live. Chronically ill people lose their previously taken-for-granted continuity of life (Charmaz, 2000). The symptoms, emotional impacts, complex medication regimens, difficult lifestyle adjustments, and efforts to navigate a complicated health care system are consistent (McGowan, 2005). Many people with chronic conditions struggle with the physical, psychological, and social demands of their 
illness without much help or support from medical care, and entire communities with physician shortages can compete with each other and other communities for health care services.

Chronicity holds different challenges compared to acute conditions. A major difference is in the relationship with their health care provider:

....some chronically ill people become so adept at monitoring and managing their illness that they break through textbook definitions, create individualized regimens, and construct new ways of living with their illness; but medical professionals may not welcome their innovations (Charmaz, 2000, p. 284).

According to Kathy Charmaz (2000), chronically ill people sometimes find that their practitioners hold an ambivalent stance toward them. Clients are asked to take responsibility for themselves, but this is often on professionals' terms rather than their own. This is an unfortunate layer of complication for the patient; "...when these ill people step outside or beyond medical authority, their practitioners may resort to medical paternalism and authoritarian demands" (ibid, p. 284). In addition to dealing with the demands related to managing an illness, people with a chronic condition must learn how to effectively negotiate with professionals. Examined through a political economy lens, this changing relationship highlights the power struggles of organized medicine, where the patient (or as will be referred here, client, which attempts to remove the reliance discourse derived from the term 'patient') is at the bottom.

It is argued that the medical model is the basis for many of these difficulties, and is ill-suited for the type of care required by people with chronic conditions. As the burden of chronicity grows and needs are better articulated, a shift away from an acute, curebased paradigm to one aligned with concepts of empowerment and self management is required. This begins by taking the chronically ill person's situation as the fundamental 
unit of concern, not the disease process within that person (because each person's expectations and objectives are different, depending on age, place, family, etc.) (McGowan, 2005). A system approach that addresses health promotion and embraces a broader definition of health is of fundamental importance here because it broadens the 'unit of concern' beyond the disease process.

Compared to acute health problems, chronicity poses more social, interactional, and existential problems because it lasts. Compared to acute conditions, there is no cure for most chronic health conditions. Unfortunately, preconceptions about acute illness transfuse ideas about chronic illness and influence institutionalized practices for handling it (Charmaz, 2000). (See Appendix A for a further comparison of the differences between acute and chronic conditions.)

\section{Primary Health Care and Primary Care}

According to Jaakkimainen (2006) there are important differences between "primary health care" and "primary care" that should be recognized. Definitions in healthcare are important, because our expectations for how care is delivered begin with how we define key terms. Put another way, words have meaning (Armstrong et al., 2001). Understanding the distinction described below is important in helping one assess different delivery models, which this thesis sets out to do.

While normally used interchangeably, the difference is captured in the following definitions:

Primary health care (PHC)-incorporates personal care with health promotion, the prevention of illness and community development. The philosophy of PHC includes the interconnecting principles of equity, access, empowerment, community selfdetermination and inter-sectoral collaboration. It encompasses an understanding of the social, economic, cultural and political determinants of health.

Primary care-is more clinically focused, and can be considered a sub-component of the broader PHC system. Primary care is considered to be health care provided by a medical 
professional that is a patient's first point of entry into the health system. Primary care is practiced widely in nursing and allied health, but predominately in general practice (Jaakkimainen, 2006, p. xiv).

Another perspective, put forth by Mable and Marriott (2002, p. i):

Primary health care involves responding to illness within the broader determinants of health. It also includes co-ordinating, integrating and expanding systems and services to provide more population health, sickness prevention and health promotion by all disciplines. It encourages the best use of all health providers to maximize the potential of all health resources.

What are the implications of this distinction? Critics of PHC claim it is too idealistic, expensive and unachievable in its goals of achieving total population coverage (Mechanic, 2003). They insist on focusing on more achievable, 'realistic' services. The introduction of 'Selective PHC' in the 1980 s was driven by cost-effectiveness models and even the WHO shifted its approach away from comprehensive PHC (Magnussen, Ehiri \& Jolly, 2004). More recently, comparative studies show that comprehensive PHC is cost effective (Starfield, 2002).

Proponents of PHC argue that a community-oriented system of PHC (one that addresses broader conceptions of health) is associated with better health outcomes. However, implementing interventions which address the community-based determinants of health are slow and varied. Lewis (2004, p.5), offers this suggestion: "Primary care is an easier concept to digest, and something the health care system is willing to be held accountable for. PHC's breadth and long-term time horizons are less well-suited to the way governments organize ministries and budgets." The point is that long-term investments are required to realize PHC objectives. The current short-term election cycle focus is at odds with the needed investments warranted to realize long-term health benefits. 
Two other definitions of PHC are of particular interest, and reinforce the broader scope of PHC. The first comes from a national initiative involving 12 professional associations across Canada, entitled Enhancing Interdisciplinary Collaboration in Primary Care (EICP). This initiative was funded through Health Canada's Primary Health Care Transition Fund, and is the first of its kind to bring together ten different disciplines ${ }^{1}$ to look specifically at interdisciplinary collaboration. They begin by stressing a population health perspective in primary health care, defining PHC as:

... responding to illness within the broader determinants of health. It also includes coordination, integration and expanding systems and services to provide more population health, sickness prevention and health promotion by all disciplines. It encourages the best use of all health providers to maximize the potential of health resources (Nolte, 2005, p. 6).

The second definition stems from Health Canada, which characterizes PHC by the following features:

- a patient-centered approach;

- 24/7 access;

- population health perspective, emphasizing health promotion and community involvement;

- voluntary participation by providers in a variety of payment models;

- access to coordinated multi-disciplinary teams (Health Canada, 2008).

Elements of these definitions which apply specifically to chronic conditions, include the population health perspective, an emphasis on health promotion, and community involvement and access to coordinated multi-disciplinary teams. More attention will be paid in Chapter Two to the fact that 'voluntary participation by providers in a variety of payment models' is part of a definition of PHC.

While the vocabulary over the past 30 years appears to support PHC, in practice we most often receive primary care. This is troublesome because primary care alone stops

\footnotetext{
${ }^{1}$ EICP partners include: Canadian Association of Occupational Therapists, Canadian Association of Social Workers, Canadian Association of Speech-Language Pathologists and Audiologists, Canadian Medical Association, Canadian Nurses Association, Canadian Pharmacists Association, Canadian Physiotherapy Association, Canadian Psychological Association, College Family Physicians of Canada, Dietitians of Canada, and the Canadian Coalition on Enhancing Practices of Health Professionals.
} 
short of providing a comprehensive, inter-sectoral approach to producing or enhancing health, and is therefore is less helpful in responding to the needs of chronicity. Perhaps most importantly, primary care is focused on individuals and families, but not the community as the unit of intervention (Lewis, 2004).

To be clear, this is not intended to understate the importance of primary care. The need for attention to acute needs that do not require attention to broader social issues particularly for those not affected by chronicity - is not diminished. What is currently lacking is the acceptance that primary care is a sub-component of Primary Health Care. We must remember that disease prevention, health promotion and quality health care are not contradictory but complementary goals (Nolte, 1997). We walk a slippery slope of ideology over pragmatism if we forget the necessity of medical intervention. In thinking about those with chronic conditions, in this thesis I assess if one model of PHC is better able to systematically address any acute needs, while equally attending to non-clinical matters.

\section{Organizing Primary Health Care to Address Chronicity}

Growing evidence supports the claim that, despite evidence that effective management and prevention of chronic conditions requires a model of healthcare that is not predominantly focused on acute systems, health care systems worldwide remain predominantly acute and cure-oriented (Willison, 2006). According to Michael Rachlis (2004, p. 91), a leading health policy analyst in Canada:

Pretty much anyone who has studied the health system in the past 20 years has become convinced that we should be providing more services out of hospitals. We built up our system heavily based on hospitals and physicians when most of our problems were acute illnesses. If your main problems are auto accidents amongst previously healthy people, our system makes sense. On the other hand, if most of our health problems are chronic illnesses like heart disease, cancer, diabetes and high blood pressure, etc., then having a system that is heavily oriented towards acute care just doesn't make sense. 
Put another way, the current system funds failure (caring for people after they get sick) rather than success (preventing avoidable illness) (Health Council of Canada, 2007).

The World Health Organization (WHO) has identified that changes to the organization and delivery of care can improve the quality of care and certain outcomes of chronic conditions (World Health Organization, 2005b). As adults aged 60 and over are expected to substantially increase in number over the next 40 years, greater attention towards finding practical strategies to enhance chronic disease management efforts is needed (Willison, 2006). According to the Health Council of Canada (2007), which is mandated to monitor and report on the progress of health care renewal in Canada, much of the burden associated with chronic health conditions is unnecessary. They call for an urgent effort to reinvigorate PHC renewal in order to improve how we manage people with chronic conditions. We need to accept that the prevention and management of chronic conditions is highly complex. Beyond the complexity of the co-morbidities and medicine regimens, an example of this complexity lies in the politics. Many effective strategies lie outside the health sector and require a commitment to long-term investments. Preventing chronic conditions will pay off in the future, but investments are required now (ibid). The Institute of Medicine concurs, claiming that in terms of chronic conditions: "The current systems cannot do the job. Trying harder will not work. Changing systems of care will... We need to change the system from an acute 'fix it' system to one that is proactive vs. reactive, comprehensive and coordinated" (Institute of Medicine, 2001, chp. 1).

There is a significant body of literature that suggests change is required. According to Jonathan Lavis (2002), the numerous and continuous calls for major reform of health 
care in Canada have recommended many changes, including service integration, user charges, primary-care reform, and evidence-based practice. Moreover, as Armstrong et al. (2001) describe, debates in healthcare reform as revolving around four central themes, each applying to chronicity. The first deals with restructuring hospitals to become more specialized, acute, and technologically dependent. Second, a priority to cut costs in every area has led to a serious shift of focus within long-term treatment. Next, the nature and extent of home care has been a very controversial topic. Finally, the reform of primary health care has led to interesting reform debates and discussions. The point here is that the various calls for reform revolve around PHC reform and the acute/chronic distinction. This thesis attends to these priorities.

As expressed in the Enhancing Interdisciplinary Collaboration in Primary Care (EICP) initiative:

It is widely recognized that a strong primary health care (PHC) system is needed to address the challenges of an aging population, and to meet the needs of the increasing proportion of people who experience chronic health conditions. A strong PHC system improves the level and distribution of population health services, buffers the effect of socio-economic factors on health and attains these outcomes at a lower cost than health systems that rely more extensively on secondary and tertiary care. As a result, primary health care renewal has been identified in Canadian policy as a key ingredient in a sustainable health care system (Watson \& Wong, 2005, p. ii).

What does this mean in the context of chronicity? Traditionally, care for chronic conditions has taken place in secondary and tertiary levels, outside primary health care settings. A growing body of literature argues that the most effective approach to managing chronic conditions begins with restructuring PHC to include: 1) The elements of good chronic condition care in integrated delivery systems that have defined populations; 2) strong clinical cultures of comprehensive services; 3) a prevention orientation; 4) data systems; and 5) centralized resources like patient education and resources. Successful chronic condition care programs rely heavily on non-physician 
personnel to conduct routine assessments, take responsibility for key preventative tasks, and provide most of the counseling and support for self management (Wagner, 1996).

An Institute of Medicine (IOM) report also lists a number of elements to address the needs of chronicity. These criteria stress continuous relationships with the care team, individualization of care according to clients' needs and values, care that anticipates clients' needs, services based on evidence, and cooperation among clinicians (Institute of Medicine, 2001). What would chronic illness care look like if these rules were in place? Firstly, every chronically ill person would have a primary health care practice team that organizes and coordinates their care (Charmaz, 2000). These individuals need welldesigned interactions between a healthcare team and client in order to fully address the range of issues that chronicity presents. Evidence suggests that the tradition of acute, problem-oriented, ideology is a barrier to such care (Wagner, 1996).

\section{The Current PHC Environment}

The shortage of family physicians in Canada is well documented (Tepper, 2004). Particularly pertinent to this thesis is the declining number of physicians entering PHC. Additionally alarming is the fact that PHC reform has actually served as a deterrent for some physicians (and medical schools) as they struggle to understand the role (and importance) of the family physician in a new team-based environment (ibid). Due to the

fact that until very recently, physicians have not been trained in the concepts of health promotion, most physicians relate more to the concept of primary care rather than PHC. This is complicated by the fact that a variety of other health care providers are interested in providing care that has traditionally been reserved for family physician, and the 
renewed efforts (in PHC reform) of bring health promotion into primary care. We are now at a critical juncture in Ontario's PHC history.

Due to a constantly changing environment and the general difficulty accessing information, the figures provided here are not exact. Numbers are also drawn from different sources. To start, the 2004 National Physician Survey indicated that there were 10,344 family physicians in Ontario (9600 FTE) (Canadian Institute for Health Information, 2006). Regarding other health care professions, there are more Registered Nurses than members of any other regulated health profession in Ontario. In 2006, there were 139,710 nurses registered with their College. Of this number, 109,034 are RN (General Class), 701 were RN (Extended Class), (i.e., Nurse Practitioners), and 29,975 were RPN (General Class) (Registered Nurses Association of Ontario website, 2007). The majority (76 percent) of these nurses work in hospitals and long-term care facilities. That said, the majority of the Nurse Practitioners are employed in PHC settings.

The most recent guiding document providing the basis for PHC reform is the Health Care Accord of 2003. This Accord signified a commitment by the Federal Government to many of the principles of PHC renewal, specifically: improved continuity and coordination of care; early detection and action; better information on needs and outcomes; and new and stronger incentives to ensure that new approaches to care are adopted. However, as a guiding document in this field, the Accord contains some serious issues of concern. First, it endorses financial incentives for physicians (more on this in Chapter Four). Second, it lacks a serious sense of urgency around the non-medical/intersectoral determinants of health, as evidenced by the medical model based indicators they plan to use to evaluate the objectives (See Appendix $\mathrm{C}$ for an example of indicators.) 
While meaningful in some ways, there are no indicators that can track how non-medical determinants are being addressed. Third, it lacks any direction on how to implement multidisciplinary healthcare teams. Granted, this is a federal document that is allowing for provincial flexibility of implementation, but it misses the point of embracing true PHC and therefore the resulting policy has little chance of embracing non-medical determinants of health. We must remember that prevention, health promotion and quality health care are not contradictory but complementary goals (National Forum on Health, Values Working Group, 1997).

Ontario has addressed these PHC reform objectives by adding 150 Family Health Teams to the existing 60 Community Health Centres. In addition to the shift to teamwork, other objectives include: reorganization of payment mechanisms and financial incentives to reward comprehensive care; continuity of care and delivery of preventative services; increased access to after-hours care; payments to subsidize Electronic Health Record (E.H.R.) implementation and payments to add non-medical health personnel to health care teams, especially nurses, nurse practitioners, pharmacists, and social workers (Glazier, 2007).

New models have come about at different times over the past 30 years attempting to address parts of the above objectives. However, due to the voluntary nature of the rollout and historical patterns of care, the uptake has not been uniform, meaning that different groups interpreted and implemented the objectives differently, resulting in different care being delivered. This long road of PHC reform is presented in the table below. 


\begin{tabular}{|c|c|c|}
\hline Model & Physician Compensation & $\begin{array}{l}\text { Approx. \# of } \\
\text { physicians }\end{array}$ \\
\hline $\begin{array}{l}\text { Comprehensive Care Model (CCM) } \\
2005\end{array}$ & \multirow[t]{2}{*}{ Blended FFS } & Limited \\
\hline Family Health Group (FHG) 2003 & & 4000 \\
\hline Family Health Network (FHN) 2002 & \multirow[t]{5}{*}{ Blended Capitation } & 648 \\
\hline Family Health Team (FHT) 2004 & & $1830^{*}$ \\
\hline Primary Care Network (PCN) 1998 & & 1919 \\
\hline $\begin{array}{l}\text { Health Service Organization (HSO) } \\
1970\end{array}$ & & 145 \\
\hline Group Health Centre (GHC) 1963 & & 38 \\
\hline $\begin{array}{l}\text { Rural and Northern Physicians Group } \\
\text { (RNPG) }\end{array}$ & $\begin{array}{l}\text { Blended compliment (payments } \\
\text { to a group based on the } \# \text { of } \\
\text { designated clients) }\end{array}$ & 25 \\
\hline $\begin{array}{l}\text { Community Health Centre (CHC) } \\
1970 \mathrm{~s}\end{array}$ & \multirow[t]{2}{*}{ Blended Salary } & 190 \\
\hline $\begin{array}{l}\text { Aboriginal Health Access Centre } \\
\text { (AHAC) }\end{array}$ & & 10 \\
\hline Various specific organizations & Specialized Models & \\
\hline
\end{tabular}

- The vast majority of the physician-led FHTs are conversions (from a FHN, PCN, HSO, FHG, etc.) and the FHT \# is more recent than the others. Thus the vast majority of these physicians have simply switched from another model, thereby reducing the numbers in these models, notably the FHG. Table adapted from Glazier, 2007.

These models, while grouped by physician compensation above (which will be addressed in Chapter Four), are most usefully distinguished in the following way: 1) Professional Contact Model, including former fee-for-service, CCM and FHG; 2) Professional Coordination Model, including PCN, FHN, GHC, FHT; and 3) the Integrated Community Model, including community-FHTs and CHCs. The differences between the models will be elaborated on in Chapters Three and Four, specifically in terms of how medical dominance has been able to influence healthcare policy. At this point the distinction is important because it illustrates the philosophy and values of the organizations, which leads to how each group chooses to address (and prioritize) the broad goals of PHC reform. 
The broad definition of PHC opens it up to considerable interpretation. Due to the variance of beliefs of what $\mathrm{PHC}$ should embody, there is reason to be concerned that despite reform efforts, status quo healthcare will be left intact, as evidenced by the synthesis paper from the National Primary Health Care Conference in 2004:

The language of the [Health Care Accord of 2003] reflects the aspirations, ambiguities and tensions inherent in moving $\mathrm{PHC}$ forward. It is at once transformative (multidisciplinary primary health care organizations or teams are more the exception than the rule in Canada) and cautious ( 8 years to ensure half the population has access to an "appropriate health provider"-not necessarily a PHC team - is about the same time it took to put a human on the moon). It also suggests that, like beauty, PHC is in the eye of the beholder. Officially, everyone embraces it, but there is no consensus on what "it" is. The public, and many health professionals are bewildered by the discussion and the terminology, but the frustration should not end attempts at clarity. Words, terms and definitions matter. Some confusions are avoidable, and others may be deliberate (Lewis, 2004, p. 2).

While similarities exist between the two models in question (FHT and CHC) each is based on a different philosophical foundation. Upon deeper inspection one finds that structural differences may result in considerable differences in how care is delivered. This thesis will address the potential consequences of different philosophical approaches on the care that is delivered to people with chronic clients.

\section{Conclusion}

Debates on defining health are not new, but reexamining these definitions in the context of chronicity is important to this study. They should reemerge because reform efforts are underway which have the potential to challenge old ways of providing healthcare. Care for chronicity in a PHC environment requires recognition of, and action on, important health promotion and population health concepts. While efforts to embrace these new ideologies are ongoing, the quest for progressive change is a long-term battle.

Determining how this change will take place, and under whose terms, will be assessed throughout this thesis. Chapter One contributed to this task by laying out what 
changes are needed in PHC, and why they are necessary. Chapter Two contributes by assessing the competing values of each of the main stakeholders involved in the debate.

The window of opportunity to making meaningful changes in PHC is small. Barriers include the hegemony of the medical model, and the short-sighted, four-year political electoral cycle. The opportunity to undertake reform, particularly when those affected are not entirely supportive of all aspects of the change, is rare. It is made more difficult by the varied and competing nature of interests and values of the players involved. These will be explored in the next chapter. 


\section{Chapter Two: Values of Key Stakeholders in PHC}

The previous chapter illustrated that the medical model, while it provides limited opportunity for people to receive true 'chronic care', dominates the healthcare landscape. Medicalized, cure-oriented treatment dominates and perpetuates the existence of a traditional environment. This disconnect can be explained by examining how competing interests and values are translated into policy.

The intention of this chapter is to locate the primary health care (PHC) reform debate in the context of longer standing relational issues. Before considering examples of PHC renewal efforts in Chapter Four, it is useful to consider the historical structures that have influenced current policy decisions. This involves paying particular attention to the values of the key stakeholders involved. By extracting key implicit and explicit messages that are evident within the health care system, and providing some examples of barriers to change, we can apply this information to future developments outlined in this thesis.

The chapter is divided into four sections. The first section details the concept of values, including what they are, why they are important and how they are used in policy. The second section elaborates on the medical model (as introduced in Chapter One), visà-vis medical dominance. Examining the historic and current role of medical dominance is critical to this study, as it sheds light on how the power of one group can be prioritized over others and ultimately influence policy. The third section looks at the role of policy makers, specifically assessing how they balance competing demands and convert them into policy. The fourth reviews the needs expressed by the public, in this case those with a chronic condition. 


\section{Values and Public Policy}

A number of stakeholders play a role in how the healthcare system is organized, and each stakeholder maintains different values, ideas, or beliefs as to how the system should work. Values are referred to as ideologies, interests, principles and goals (Giacomini, Hurley, Gold, Smith \& Abelson, 2004) and have been defined by Lomas (2000, p. 142) as emerging from "a complex interaction of interests with beliefs and ideologies." Therefore, values are complex and inter-relational. People can maintain personal and professional values, which can at times compete with one-another.

Values are important to this debate because PHC is value-driven. In fact, health care in Canada is based on a core set of values which found within the principles of the Canada Health Act (1984). The principles of the Act include public administration, portability, accessibility, comprehensiveness, and universality. As in the 1980 s, recent governments in Canada have again commissioned task forces, commissions (Building on Values - the Future of Health Care in Canada, 2002), and forums (National Forum on Health Care, 1997) to garner advice on how to proceed with health care reform. This advice was both value- and expert-based, and while comprehensive, in essence offered no surprises.

The work above highlighted not only the importance of a value-based health care system in Canada, but also the varied and conflicting values that exist. For instance, the National Forum on Health Care (1997) claimed factors such as efficiency, effectiveness, and stewardship are values of Canada's healthcare system. Moreover, as Giacomini (2004) describes, equity, fairness, economic viability, individual rights and responsibilities, and even health status have been identified as values. Further still, 
values can include material items or physical entities (e.g., hospitals, MRIs, etc.). This assortment and variance of values is consistent with the definition of health as presented in Chapter One; health and values are both personal and subjective. According to Maxwell (2002, p. 1543) "...health care, no matter how technologically advanced in becomes, is profoundly a human experience."

The issue at hand is how values discourse is represented in policy. According to Giacomini (2004), the manner in which values are translated into policy is blurred and inexact, and also open to 'hidden dissent'. Despite the widespread belief that our healthcare system is 'values based', in many ways the main stakeholders disagree on what these values essentially are (ibid).

As demonstrated by Maxwell (2002), the difficulty with polling questions is found in the fact that they do not enable citizens to consider fundamental trade-offs and to find ways to reconcile conflicting values. For instance, access and quality are intricately linked. Increasing access can have a negative effect on the quality of care. Similarly, equity and efficiency are often in tension. In some ways, this decision making process is at the heart of this thesis. Who chooses between the above concepts and between more fundamental issues such as medical model ideology versus a more holistic definition of health (also distinguished by PHC versus primary care) is central to this argument.

Despite the ambiguity of values, a commitment to core values persists. Complicating this commitment is the current political and economic climate, which forces decisionmakers to prioritize certain values and interests over others. This dilemma is at the heart of this analysis - how and why political decisions determine the winners and losers. How do economic circumstances or similar powerful institutions determine or influence 
political institutions and processes? How competing interests are dealt with in PHC policy is the focus of this chapter. Specific attention is paid to the voice of the client, in this case the person with a chronic condition who is in need of PHC. As the least powerful group in the mix, their voice can go unheard. According to Maxwell (2002, p. 1543) health care is "...about me, the individual. But it is also about us, the collectivity". Unless all voices can be heard, the health and well-being of the collective is in jeopardy.

\section{Levels of Analysis}

Bolen (2000) describes five parties involved in health care as a partnership pentagon, including policy makers, health professionals, academic institutions, communities and health managers. While this is a 'clean' presentation of the players involved, it does not address the uneven playing field of healthcare, nor does it include the influence of forprofit corporations.

While each level or group has a variety of common needs, interests and values, it is inexact, unfair and dangerous to generalize or compartmentalize the various and sometimes conflicting interests within each group. For example, the medical profession is highly segmented with differences based on gender, age, specialty, and location of practice. However, for our purposes, I concentrate on presenting the general attitude of each group (which can often be taken through the articulation of their organized associations) while acknowledging the internal differences.

\section{Medical Dominance}

Within the sociology of health, medicine has most often been viewed as being the dominant role within a network of relationships. In this case we speak of the medical profession as a group that has dominated relationships with other key stakeholders. By 
definition, dominance implies power of one person or group over others. Starr (1982) defines medical dominance as the power of doctors to control the actions of others through commands and cultural authority deriving from the value accorded to medical knowledge. Both these definitions suffice here. My objective is not to critique the historical accounts or opinions available on the topic.

I do not intend to add to the existing literature which examines the status of medical dominance (e.g., is medicine still dominant?). Rather, based on the wealth of literature on the topic, I assume that a health care hierarchy remains mostly intact and medicine sits atop. $^{2}$ What is important here is to provide a foundation that will allow us to question the impact of the historical dominance of the medical model on two current models of PHC. For instance, how has medical dominance affected the shift towards multidisciplinary teams, which has been shown to be a critical factor towards providing better PHC care for people with chronic health conditions?

The historical rise of medicine is not described kindly in the literature (Friedson, 1970; Willis, 1983; Friedson, 1988; Coburn \& Willis, 1998; Coburn, D’Arcy \& Torrance, 1998; Coburn, 2004; Coburn, 2006). Friedson (1970) characterized how medicine secured its dominant status at three levels: one, control over their own work (characterized as autonomy); two, control over the work of other health care providers (i.e., authority); and three, control over the concept of health in the wider society (i.e., sovereignty). A description of each level, with consideration on the impact today, is provided here.

The ability of medical practitioners to control their work (autonomy), and the parameters of the profession, was an early example of the political nature of health care.

\footnotetext{
${ }^{2}$ For a detailed historical account, see Willis (1983 \& 2006) or Torrance (1987)
} 
The group quickly established the ability to control the supply of physicians by partnering with elite universities. Limiting the number of practitioners also elevated their incomes which further enhanced their prestige (Coburn et al., 1998). This included controlling the education process, thereby ensuring the system and delivery of health care was based on their expertise. The outcome was a policy monopoly, which according to David and Gent (2000), exists in health care when policies are based on the technical expertise of one group. This resulted in limited ability by partnering stakeholders (namely the state) to exercise control on the autonomy of physicians (David \& Gent, 2000). These relations of power and inequity were embedded with the introduction of organized medicine, and their effects remain today causing barriers to change.

What is the impact of autonomy today? Medicine began as a privileged occupation and continues as such. Its autonomy was rarely questioned or challenged, and this mindset has been entrenched in the training and culture of the group. As a result, health care decision-makers today must often appease this powerful group.

An example today is evident in the group's reaction to new forms of reimbursement. Changing the fee-for-service arrangement has been at the crux of most reform efforts in Canada (Ontario Health Review Panel (1987); Premier's Commission on Future Health Care for Albertans (1989); Minister's Implementation Committee (1990); British Columbia Royal Commission on Health Care and Costs (1991); Rachlis (2006)). However, due to the powerful interests of the group, change has not been easy. According to Michael Rachlis (2006, p. 38):

[t]here are a lot of other reasons why the status quo has been in place, but one of the reasons is that the dominant interests within the health system, especially that of doctors, are very powerful and there usually isn't an effective coalition on the other side to change things. 
Movement away from fee-for-service payment is not endorsed by the Ontario Medical Association (OMA). The OMA has not been prepared to implement new funding models, as any change has been perceived a loss of autonomy. Not surprisingly, negotiations in this matter have only involved governments and the OMA, and have not included the views of other health occupations (Fooks, 2004).

Another component of this changing reimbursement deals with incentive payments. As an alternative to straight fee-for-service, physicians are paid a premium (or incentive) for delivering certain preventative screening services. This is concerning for a few reasons. In establishing the preventative care incentives, the Ministry of Health and Long Term Care intended to promote more preventative care for clients, ensure a healthier Ontario population and develop a mechanism to quantify this work. The decision to establish multidisciplinary teams within a financial environment where physicians are rewarded for the work done by others has had a particularly negative impact, for the following reasons: 1) Nurse practitioners (NPs) feel devalued, and their work becomes invisible and the work environment is affected. 2) NPs' scope of practice can be limited within practice settings. For instance, NPs are reporting that their practice is being focused on the incentive activities because their physician partners benefit from NP activity. Others (Nurse Practitioners' Association of Ontario, 2008) report that they are seeing fewer clients because the physicians do not want conflicts over compensation. In general, these payments are destructive to a collaborative working relationship, and are an example of how physician interests are being placed ahead of those of other groups involved. 
Furthermore, evidence of the above is seen in the following quotes of an OMA policy position paper: "The physicians or group of physicians should be the only healthcare providers to whom patients roster" (Ontario Medical Association, 2007a, p. 3). This opposes what has been presented as best practice in PHC and CDPM literature, namely the importance of team-based care. This is a prime example of efforts to control and exert power, and maintain their superordinate status. The group does not embrace the true intention of the shift to team-based care, which has been presented as increasing access (by increasing the number of providers) and also quality of care (by providing clients with a team of providers, most appropriate for each client.)

The cumulative impact of these issues has been to create the perception that NPs are not valued members of the health care team with the expertise and knowledge to increase access to PHC for clients. Furthermore, the rostering policy and incentive payments impact the autonomy of NPs and presents a challenge for this emerging profession.

The second level of medical dominance is control over the work of other health care providers (authority). This level is particularly pertinent to this debate, considering the multidisciplinary teamwork goals of PHCR today.

Control over the health care division of labour was intentional and established from the start. Willis (1983) claims that medicine directly or indirectly controlled other health care providers either through directly controlling their education or through control over the labour process, i.e., patient care. The state was involved, but only indirectly and in line with medical wishes (Coburn, Rappolt, \& Bourgeault, 1997).

According to Coburn et al. (1997, p. 335), "medical men came to rule their own occupation, and to exclude, limit, or subordinate, competitor occupations such as 
chiropractic and midwifery, dentistry and pharmacy, and nursing." This meant that the medical profession solidified a hegemonic hierarchy early on, allowing basically absolute autonomy for physicians and also control over their 'lesser' colleagues.

Freidson (1988) cites four ways in which the work of non-physician providers has been controlled by physicians. Firstly, most of the technical knowledge used by allied health tends to be discovered, enlarged upon, or at least approved by physicians. Secondly, tasks performed by allied health tend to assist rather than replace the main tasks of diagnosis and treatment. Thirdly, allied health providers tend to be subordinate because their work is done at the request or demand of physicians. Finally, the prestige assigned to allied health by the general population is less than that of physicians.

Additionally, the major occupational problem is the fact that other providers are forced to work under the physician, and they are given legitimacy through a relationship to the physician's work (Freidson, 1988). Therefore, they have two choices - learn to find satisfaction with the hierarchy, or find some independent source of legitimacy. In the former case they remain part of the medically dominated hierarchy, in the latter they assume a position outside though parallel to the hierarchy.

What is the impact of this authority today? A good example is the reaction by many physicians to the current PHC policy shift toward team-based care, which essentially redistributes work formally done only by family physicians to a team of allied providers, such as nurse practitioners, social workers and dietitians. While certain groups of physicians welcome the change, even embrace it, many strictly oppose it. This opposition is generally based on three reasons: reimbursement mechanisms are not 
adequate to pay for new team members; legal ramifications of working in teams; and a general attitude that this is physician work and should not involve 'lesser' providers.

Examples of how this attitude persists today are seen in a recent OMA policy paper (Ontario Medical Association, 2007b). For instance, the OMA (2007b, p.3) contends that "Within collaborate teams in primary care, the comprehensive primary care physician should be acknowledged as the clinical lead." This comment contrasts with PHC reform literature which suggests that nurse practitioners often have a better relationship with client (Bailey et al., 2000), one that is more empowering for the client, and the coordinator of care should be based on the most appropriate individual rather than title of profession.

The same OMA document $(2007 \mathrm{~b}$, p. 3) states: "The primary care physician should be the only member of the PHC team responsible for determining when the skill set of the team has been exceeded and when a referral is necessary." This is an example of maintaining power within a working relationship. It is also inefficient, because in many cases the physician will be duplicating work that has already been done by another provider. It also perpetuates a hierarchical relationship.

The third level of medical dominance involves control over the concept and definition of health in the wider society (sovereignty). As described in Chapter One, the medical model and its reliance on objective science as the only truth has guided the definition of health. The impact of the definition of health on how we care for chronic conditions is considerable, as it deals with how we define health and therefore how we design systems to treat it. 
Why are other providers forced to work under medicine? Why is their role legitimated only through their relationship with the physician? What is the effect of this relationship? Some argue that this was intentionally established by medicine, in efforts to secure their position at the top of a medical hierarchy. Yet the advances in medicine and benefit to society during this time should not be overlooked. Simply put, these individuals have experiences and maintain viewpoints that should be represented in policy. The fact remains that physicians have fought to maintain authority over other health occupations, despite evidence (Suschnigg, 2001; McColl et al., 2006) that the participation of other health care providers in a team-based approach is more favourable. The point is that these examples set in place the hegemony of medicine, and the barriers they created still exist today.

According to Coburn (2006, p. 435):

\begin{abstract}
Medical power became salient because it was obvious that the profession can and did, to various degrees and with various degrees of effectiveness, use its multiple forms of power, authority and influence to orient health care systems towards its own interests rather than necessarily the interest of patients, the public, or the state... while individual medical men and women could be altruistic and community-oriented, the profession as a corporate entity often reflected more mundane interest.
\end{abstract}

Historically, there is evidence that the medical profession has been able to maintain a conscious superiority over other health care providers. However well intentioned, the decisions made by medicine during this period were often in their own best interest. One example, highlighting the lingering effects of the historical hierarchy, made by a medical official of the federal department of Health, who stated "we do our utmost to maintain at every turn the interests of the practitioners of Canada as well as organized medicine" (McGinnis, 1980, as cited in Coburn \& Willis, 1988, p. 335). This indicates that health policy placed an added importance on doctors' needs and interests, maintaining a hierarchical structure. 
Compared to the examples of autonomy and authority, today physician sovereignty is in decline. Examples of these challenges include the health promotion and population health movements, the patient's rights movements, and also changes to the boundaries of medical knowledge (Coburn \& Willis, 1988).

Of particular importance to chronicity are the health promotion and population health movements. These revolve around the social determinants of health as reviewed in Chapter One, and represent a shift from infectious and acute disease to more chronic conditions. Physicians, as the major experts in acute care, have been forced to give way slightly to newly emerging chronic-care occupations (Coburn \& Willis, 1988). Chapter Four examines how medicine, and the models in question, are equipped to deal with these changes.

The population health movement has also led to the development of evidence-based medicine, resulting in clinical guidelines and best practices (Lewis, 1995), which have essentially forced physicians to provide the rationale for treatments. In addition, it provided non-physicians with a tool to judge and evaluate physician work. On the other hand, despite becoming a powerful instrument in efforts to level the playing field, concerns remain. Increasingly, reimbursement is becoming dependent on adherence to guidelines and best practices (Lewis, 1995). This serves to commodify healthcare delivery through connection to incentive payments.

Clearly, physicians remain a cornerstone of the health care system. The point here is not to be overly critical of the occupation, but rather acknowledge the attributes of other providers and essentially break down the historic hierarchy that has for the most part kept 
the status quo intact. In light of chronicity and the shift away from acute system, this is meaningful.

On a policy level, medicine is now more reactive than it was in the mid-to late $1990 \mathrm{~s}$ (Coburn et al., 1997). No longer is the group given full range on healthcare policy, and the fact that an engaged debate about multidisciplinary team work and alternative modes of funding is taking place is evidence of that. While medicine remains very effective at blocking reforms or shaping others, it does not create or dictate the reforms. That said, medicine in PHC today has been shown to influence the payment schemes (evidenced by that fact that 'physician choice of payment model' has been included in definition of PHC). Additionally, medicine remains the major barrier to a more appropriate division of labour in health care, and the implementation of such dramatic changes is mainly stalled by medicine.

Examples of rationalization 'from above' include the state's increasing tendency to cap the costs of care through attempts to control utilization and to make health care more effective and efficient. This rationalization, whether involving more competition within health care, an increased 'managerialism,' or greater or lesser privatization, or some combination of these, almost always implies intrusion onto territory previously controlled by medicine (Coburn \& Willis, 1998). This argument further contends that there is no room for tax increases-in fact the global economy and public expectations demand tax reductions.

In summary, the tradition of medical dominance is at odds with multidisciplinary team work and is also at odds with the needed shift to a more egalitarian client-physician relationship. There are troubles with clinicians working in isolation to treat their narrow 
aspect of what has been accepted as a multi-factorial. Not only is this highly inconvenient for clients (time and transport), it results in fragmented care and in the end poorer outcomes.

\section{Policy Makers in PHC}

The concept of 'the state' includes a multitude of players, ranging from federal and provincial governments, to sub-central levels of government, the legislature, military, judiciary, provincial executives and bureaucracy (Panitch, 1977). As such, theorizing and evaluating the role of the state in policy decisions is highly complex. This section deals specifically with the state through the policy-makers of Ontario's Ministry of Health and Long Term Care and assesses how this agency attempts to balance the values of each stakeholder and translate them into meaningful policy.

In Canada and elsewhere, medical sociology theory has been applied to many government policy documents, urging policy makers to think more broadly and embed tangible health promotion and population health perspectives within the delivery models. A review of key Canadian health policy strategy documents and commissioned reports as they relate to caring for chronic conditions in a primary health care setting, with particular attention to health promotion and population health perspectives, is helpful at this point. The intention is twofold; first to highlight the strong commitment by policy makers to research on this important topic; and second to provide more background to inform the current policy environment.

The Lalonde Report in 1974, "A new perspective on the health of Canadians" emphasized the need to accept the social environment as a determinant of health. This was a seminal work that bridged the goals and objectives of health promotion with 
primary care. Due to the discussion and interest this report raised, it is widely touted as the most cited Canadian health care policy paper. In fact, it is considered the first report by a major industrialized nation to state that health is determined by more than just biological factors (Health Promotion Agency, 2008).

In 1986, the Ottawa Charter on Health Promotion clearly identified that health services should incorporate health promotion concepts such as community development, empowerment, and advocacy and called upon the health sector to move in this direction. For instance:

\begin{abstract}
The role of the health sector must move increasingly in a health promotion direction, beyond its responsibility for providing clinical and curative services. Health services need to embrace an expanded mandate which is sensitive and respects cultural needs. This mandate should support the needs of individual and communities for a healthier life, and open channels between the health sector and broader social, political, economic and physical environmental components (World Health Organization, 1986, p. 4).
\end{abstract}

In 1994, the Federal/Provincial/Territorial Advisory Committee on Population Health presented a paper on strategies for population health to the Ministers of Health. It emphasized the need to strengthen public understanding about the broad determinants of health, to enhance public support for and involvement in actions to improve the health of the overall population and to reduce health disparities experienced by some groups of Canadians.

More recently, in 2002 the Romanow Commission report urged for increased investment in the social and economic determinants of health. The Kirby Report on the Federal Role in Health Care concurred, claiming that 75 percent of our health is determined by our physical, social and economic environments (Kirby, 2002).

In 2007, the Health Council of Canada delivered their inaugural report identifying priority areas for action, which included a broad inter-sectoral approach. Inter-sectoral work is critical in the context of achieving goals to align services with the definition of 
health. As discussed, the most important determinants of health lie outside the formal health system, and therefore the health sector must work with others departments. These goals will be achieved only if our primary health care system is built to take health promotion and population health goals as seriously as it takes acute medical problems.

In 2005, the Integrated Pan-Canadian Healthy Living Strategy, approved by Federal, Provincial and Territorial Ministers of Health, was based on a population health approach and envisioned a healthy nation in which all Canadians experience the conditions that support the attainment of good health by improving overall health outcomes and reducing health disparities.

As described in Chapter One, this holistic focus (compared to an acute disease focused perspective) is critical for those with chronic conditions. However, Ontario has a long history of paper-based solutions and reports that have gone without implementation. In fact, according to Evans:

\begin{abstract}
No one seriously challenges the evidence for this broader viewpoint, yet the medical care debates proceed as if these broader determinants were irrelevant to decisions about how much should be spent for narrowly defined medical services. Indeed, the continuing pressure for expansion of traditional medical care has tended to preclude the development and support of programs addressing the other and more significant determinants of health status (Evans, 1993, p. 17).
\end{abstract}

This is important, because according to Paul Pierson, policies, once they are put in place (or not put in place), can be self-reinforcing through a process often referred to as "path dependence." This is accomplished in a few ways, including the creation of institutions that support the policy, shape the values of policymakers, stakeholders, and the public. This process also adds over time to the social, political, and economic costs of shifting to another path. The costs of switching are usually immediate. The benefits, however, occur later. As such, path dependence is supported by the short time horizons of political actors (Pierson, 2000, p. 253). 
How does one interpret this disconnect between research and practice? Today, the state is often challenged for subscribing to neoliberal ideology, which includes a focus on cost containment, privatization, deregulation, shrinking states and freeing markets (World Health Organization, 2005a). This is particularly important to Canada, as the desire by the public to sustain the Keynesian welfare state (in this case a comprehensive, universal and publicly administered health care system) conflicts with the state's desire to eliminate deficits, reduce debt and lower taxes. These tendencies have been shown to conflict with welfare state priorities (social safety net for all, regardless of ability to pay), and form the basis for most policy debates today.

While it is beyond the scope of this thesis to theorize the state, it is useful to consider the true impetus of PHC reform. As will be shown, some political objectives of reform are contradictory (for example, access and quality; efficiency and equity), and how these objectives are captured in policy requires acceptance that the trade-offs are not equitable. This issue with the inequity is that the interests of the powerful are acted on first. In the end, those who need the system the most have the least power and are therefore not heard.

\section{Public Values}

Public values as used in this study pertain to those people, and their families, who have a chronic health condition and are in need of PHC attention. Their needs and values were expressed in Chapter One, and revolve around: integrating health promotion in PHC; having access to a multidisciplinary team of health care providers; and being engaged in their care. A recent report by the Health Council of Canada (2007), illustrated a number of factors that are important to people with chronicity. They are useful to 
consider here because they often shape the personal experience and values of those with chronicity. These include: a more integrated entry point for patients; a broad range of health promotion and illness prevention services and medical treatments; more timely access and treatment, including enhanced 24/7 access; better coordination; and better quality care (Health Council of Canada, 2007). While these factors have been identified as values for those with chronic conditions, it does not necessarily mean they are values of everyone. Quality may mean more to someone who requires a provider to have a comprehensive view of their personal situation, while someone in good health may value access.

Assessment of public values toward the health system indicates that the public's values are not reflected as closely in the current system as they once were. Public opinion polls indicate values of self-reliance, autonomy and choice as well as those of compassion and future investment (Abelson \& Eyles, 2002). While at first glance contradictory, they are representative of the difficult reality of policy makers - taking the variety of values across population groups such as the young and old, the affluent and the poor, across regions and governing parties and translating it into policy. An example of this difference is seen in the continued focus on the medical model based acute care system that emphasizes choice and autonomy despite the growing number of people living with chronicity.

The literature highlights some consistent concerns from the public. Firstly, there is growing concern about timely access to an appropriate provider. Secondly, there are significant care gaps for those with chronicity. Specifically this means assistance with 
system navigation and an increased focus on preventative care, health promotion and public health (Frankish, et al., 2006).

According to Roy Romanow (2002), Canada's health care system is built on an inexact accumulation of compromise and accommodation between citizens and governments. It unfolds, develops, and changes on the basis of individual and collective human decisions. And while one would like to believe that all Canadians, and all elements of the system, are committed to the same set of core values and principles, such as equity, fairness, and the allocation of resources based on needs, each stakeholder maintains their own values, expectations, and interests (ibid). For example, values may be shaped by interests such as those held by professional organizations looking to protect their organizational culture, governmental ability to balance fiscal demands and social policy, or by the impact of the loss of the only grocery store in a community going out of business.

The above example highlights how people collectively and individually make their own history, although not under conditions of their own choosing (Armstrong et al., 2001). The establishment of commissions, such as those outlined above provide additional opportunities for shifting beliefs through the commissioning of ideas (Jensen, 1994), and identifying the tensions underlying these values and interests, and the potential methods for resolving them.

\section{Conclusion}

In this chapter, I argue that recent healthcare policy decisions are largely influenced by the medical model, the dominant paradigm within healthcare and therefore determining the type of services that are available. Secondly, I state that within a 
democratic state some priorities are favoured over others; as a result, power struggles dictate outcomes more than actual need.

Additionally, political economy as applied to systems of caring for chronic conditions builds on the medical sociology theory regarding determinants of health and the medical model as presented in Chapter One. It considers the structures, systems and policies that cause these conditions (Hayward \& Colman, 2002). This line of thinking is critical to the insight into how and why decisions have been made and what these decisions mean to PHC in Ontario. Our focus is on the relationships between key stakeholders and how these relationships impact policy decisions, and therefore the health care system overall.

Reforms are being planned, contemplated and implemented, sometimes in direct contradiction to other policy directions. Policy-makers in their quest for answers have, in recent years, accepted the importance of PHC as a key strategy in achieving these goals. Questions are posed as to why certain decisions have been made, including the policy decision on which the research question is based, i.e., looking at a new model of PHC (FHT) delivery in relation to a longstanding model of PHC (CHC), is one better equipped to provide chronic care?

Paying close attention to the power relations of the key stakeholders provides insight into why some objectives can take priority over others (Hutchison, Abelson \& Lavis, 2001). According to Bourdieu (1986), human subjects are actors whose agency, or capacity to act deliberately or to exercise willful power is constrained by the social structures through dialectical relationships. People, groups, ideas and policies are actively created within particular social relationships which inherently privilege some 
groups over others (Lavis, 2002). These relations of inequity and power and the resulting policy decisions were the focus of this chapter.

This thesis is guided by the work of a variety of political economy scholars. Clement (1989), suggests that political economy focus on processes whereby social change is located in the historical interaction of the economic, political, cultural and ideological moments of social life, with the dynamic rooted in socio-economic conflict. I maintain this focus, by looking at PHC reform through the main barriers to change. These barriers can be identified by examining the impact of the interests of key stakeholders on public policy. In the following chapter, a framework is presented that allows one to take account of how competing interests and objectives can result in different forms of PHC delivery. 


\section{Chapter Three: A Framework for Assessing Chronic Care in PHC}

The intention of this chapter is to present a framework for comparing the two $\mathrm{PHC}$ models in question. This framework is firmly based in the health promotion literature and assesses the ability of each model to shift from a medical model ideology toward a more holistic approach. It also includes pertinent traditional elements used to assess primary care, in efforts to offer a balanced presentation. It is designed to challenge the existing 'agency', in that certain individuals have been able to dictate the type of health care that is available to people with chronic conditions (and in doing so, these individuals also decide what type of health care is not available). This includes considering the values of each group as analyzed in Chapter Two. The framework is also built to compare the 'structure' of each organization, namely identifying the priorities of each model through an assessment of the composition of the multidisciplinary team. This structure develops an organizational culture that in turn determines the care and even influences agency.

In Canada, a number of indicators have been developed to assist in PHC evaluation (Glazier, 2007). However, many of these indicators are rooted in the medical model and do not address health promotion or other determinants of health. For instance, studies claiming to evaluate preventative care define 'prevention' as childhood immunizations, flu shots, and screening for cervical cancer and colorectal cancer screening (Jaakimalnen, 2006). While important clinical services, these examples stop short of addressing the full scope of what is important in PHC. Health promotion, according to the WHO, "...works to enable people to increase control over their health and its determinants by developing personal skills, embracing community action, and fostering appropriate public policies, 
health services and supportive environments." (WHO, 2005, par. 7) The fact that frameworks for evaluating PHC lack appropriate attention to health promotion is a major problem.

Yet, despite a reliance on medical model indicators, comparative studies have been unable to position one model over another, due to minimal and contradictory evidence (Hogg et al., 2007). The most recent study on this topic, a meta-analysis of the comparative research on PHC models in Ontario, confirms that there is a lack of convincing evidence for any one model over another (ibid). This is important because many frameworks prioritize medical model indicators and should therefore favour PHC models that employ a medical model ideology. Therefore, changing the perspective on which to assess these models could reveal significant differences.

Frameworks for evaluation do not mean the same thing to every group involved. For example, in one case, the framework for "primary care" addresses the key issues for physicians: compensation arrangements, contractual arrangements with regional health boards, clinical autonomy and independence, service expectations (e.g., on call; hospitalbased services) and accountability (LeGrow, 2001). In another, a framework for assessing PHC is based on ensuring a holistic approach, in partnerships with clients and collaborating to design mutually agreed care plans (College of Nurses of Ontario, 2007). Another framework is based almost directly on the principles of PHC, namely community partnerships, population health approach, inter-sectoral care, accessibility, appropriateness, continuity of care, efficiency and affordability (Manitoba Ministry of Health, 2002). Despite common titles, the content of each can vary depending on the group concerned. The framework presented here offers a balanced approach to what is 
currently used, with a clear emphasis on health promotion concepts. These differences suggest a need to clearly defend what is included in an evaluation framework, and justify why certain elements are prioritized over other important factors.

\section{Framework Described}

This framework pays close attention to the needs of people with chronic health conditions, as identified in Chapter One. This includes an emphasis on health promotion over medical model ideology, and also pays close attention to elements of key Canadian health policy documents (e.g., Canada Health Act and the Health Care Accord), as they pertain to PHC and chronicity.

The criteria that make up the framework are largely accounted for within the two existing frameworks that will be used, including Ontario's Chronic Disease Prevention and Management (CDPM) Framework (see Appendix D), and Barbara Starfield's $A$ Framework for Measuring Primary Care (see Appendix E). A combination of frameworks was required, because in the case of the CDPM framework, it is attuned to chronic conditions in general and not designed specifically for PHC. Starfield's work, while primarily primary care oriented (as opposed to PHC), provides clear and relevant criteria on which to evaluate the models in discussion.

In addition, I have isolated certain components that are identified only within definitions of the frameworks above. For instance, Governance is addressed within the CDPM model, within Decision Support, while in this context it warrants separate attention. Also, an explicit political economy of health approach is embedded within all components; thus, I pay close attention to the competing values and relationships between stakeholders. 
Each criterion will be addressed firstly by describing its overall importance or value to PHC and chronicity. I then illustrate how each criterion will be defined and operationalized in this study. At the same time, it must be recognized that all elements overlap and cannot be looked at in isolation. Due to the complex and multi-factorial role each criterion plays, attempting to rank elements is undesirable. The order in which they are presented is based on the order in which the concepts were introduced throughout the paper, with governance reserved as the final component. This thesis embraces the importance of evaluating PHC models based on the needs of chronicity, i.e., using criteria not based on medical model ideology. The difficulty in measuring the impact of longterm health promotive activities has been acknowledged. It has also been acknowledged that this type of measurement is at odds with the current return-on-investment and shortterm political election cycle. As a common framework has yet to be accepted for evaluating the work of teams in this context, this thesis may support the growth of evaluative literature in this area.

\section{Community Action and Supportive Environments}

This element is drawn together by combining two criteria of the CDPM model. It is useful because of the direct attention paid to health promotion and community health concepts, which remain largely on the fringes of clinical practice, due in part to the perceived 'non-urgent' nature of health promotion when compared with clinical/medical care. As described, the medical model has been the default model of care (Frankish et al., 2006).

Both community action (defined as encouraging communities to increase control over issues affecting health) and supportive environments (defined as removing barriers to 
healthy living and promote safe, enjoyable living and working conditions) are drawn directly from the Ottawa Charter of Health Promotion, 1986. This document is an international charter and is widely acknowledged as a guiding document in the field of health promotion.

This criterion is employed here in an effort to emphasize the importance of health promotion and community health in PHC and chronicity. While chronicity may be the antithesis of the medical model, health promoters would claim that health promotion is a more appropriate adversary. Health promotion comprises multiple, interconnected concepts that need to be incorporated into the daily practice of PHC. A narrow technical approach is inadequate for intervening in chronic health problems that have a social, economic, behavioural and/or psychological basis. With increased focus on health promotion, health services may be a more effective determinant of health. Community health overlaps with health promotion activities in many ways, but generally can be distinguished through its community (rather than individual) approach to achieving broad health outcomes.

These factors differentiate primary care and PHC. According to Frankish et al. (2006, p. 174), "Primary health care is the natural entry-point to reorient a health system towards health promotion." If that is the case, both models will be assessed as such. This involves assessing the ability of each model on the basis of acknowledging that the physical and social environment is an issue to those with chronicity. More importantly, we must consider if or how these models address causal issues such as accessible transportation and adequate walking trails. Much of this work is essentially 'hidden', and not as easy to quantify as traditional indicators. 
This section evaluates the ability of each PHC organization to embrace health promotion and community health, which is important to consider for two reasons. First, the inclusion of health promotion will redistribute the power among other team members. Second, it challenges the hegemony of the medical model ideology. These elements ensure that health care delivery is inclusive of the needs of chronic condition clients.

Specific questions that will be considered include: What resources are dedicated to health promotion activities? What specific programs and services are offered that demonstrate a commitment to health promotion? Is there a defined community? What specific services exist that improve community health?

\section{Teamwork}

The benefits of a multidisciplinary team to people with chronic health conditions have been well established. Put simply, the multi-factorial composition of health make traditional client/doctor relationships difficult. The reality is that no single practitioner or type of practitioner can meet the health needs of someone with a chronic health condition completely. What is required is a shift from a provider focus, where responsibilities are distinct and separate, to a client focus, where an integrated, multi-service team of providers and professionals (within and beyond the health sector) work together to address needs (Frankish et al., 2000).

Additionally, client involvement as part of the team is an important piece that is often left out of teamwork discussions (Clark, 2003). Clients who lack a sense of control or capacity over their health are less likely to report feeling healthy or happy. Alternatively, people report being happy if they feel they are a partner in their care. Empowering clients to let them make informed decisions about their wellbeing, health and social care 
requires a sophisticated approach to teamwork to meet clients' needs and expectations

(Holman \& Lorig, 2000).

Encouraging teamwork in health care is not a new concept. However, more and more, interdisciplinary collaboration is being suggested as a key strategy for providing the best quality and most effective care for people who use PHC services. For example, interdisciplinary collaboration was identified as an important goal of the Primary Health Care Transition Fund, the First Ministers' Accord in 2003 and the First Ministers Meeting on the Future of Health Care in Canada in 2004 (Watson \& Wong, 2005). Beyond the above policy recommendations, public opinion polls also suggest that clients are responsive to these changes (National Forum on Health, 1997).

However, not only do views of teamwork differ; in some cases they conflict. This suggests there is a strong need to develop common language among team members in order to work effectively. Teamwork in health care has been defined by the WHO as:

Co-ordinated action carried out by two or more individuals jointly, concurrently or sequentially. It implies common agreed goals, clear awareness of, and respect for others' roles and functions. On the part of each member of the team, adequate human and material resources, supportive co-operative relationships and mutual trust, effective leadership, open, honest and sensitive communications, and provision for evaluations (Kekki,1990,p. 3).

Collaborative practice, which is a component of a high-functioning team, has

been defined as:

...an interprofessional process for communication and decision making that enables the separate and shared knowledge and skills of care providers to synergistically influence the client/patient care provided. A foundational component of collaborative practice is 'equality' within the team framework and not hierarchy (Way, Jones \& Busing, 2000, p. 2).

What precisely does collaboration provide for everyone involved?

For clients, collaboration can improve: self management of health conditions; clinical markers for acute and chronic diseases; quality of life; and client satisfaction. For the community, collaboration can lead to: engagement of the community in collective action to address relevant issues or concerns; increased community leadership on key issues; 
increased availability and coordination of supports to meet community needs; new or modified community policies for priority health issues; and enhanced community satisfaction...For health care providers, engagement in collaborative work results in increased job satisfaction, appropriate workload distribution among team members, and enhanced knowledge and skills for individual providers. In order to function well, the team requires a common value system (Canadian Alliance of Community Health Centres, 2007, p. 7).

However defined, teamwork is hard to achieve. Research identifies not only the benefits, but also the complexity of multidisciplinary practice (Watson \& Wong, 2005). According to one report: "Structural, historical and attitudinal barriers can and do contribute to difficulties which inhibit teamwork. Problems can arise from competing demands, diverse lines of management, poor communication, personality factors, plus status and gender effects" (Royal Pharmaceutical Society of Great Britain and the British Medical Association, 2000, p. 5).

Therefore in assessing how able each model is to embrace teamwork, I consider the how traditional barriers and demands are addressed. This includes addressing the following questions: How equipped are teams to recognize and value the role of all team members? How equipped is the team in sharing decision-making authority? How equipped are teams to select a leader based on values, experience rather than by professional title? How equipped is the team in making the client a member of the health care team?

\section{Reimbursement}

Reimbursement is as important in PHC today as it ever has been, as it is part of a series of proposed changes (others including multidisciplinary teams, increasing patient access to primary care, and increasing access to multidisciplinary teams including nonphysician health professionals) under the umbrella of primary health care reform (Health Canada, 2007). Reasons for reform are varied, as reviewed in Chapter One. Generally, 
the goals of reform are to increase access to PHC (through use of multidisciplinary teams) while controlling costs.

Reimbursement is critical, as the method by which physicians are paid has been shown to influence their (and their organization's) behaviour (Gillett, Hutchison, \& Birch, 2001). Simply, how a doctor is paid can directly influence the care someone receives. History shows us that the effects of professional socialization and medical culture should not be taken lightly when assessing the impact of payment schemes on expected changes and programs and services (ibid).

A key component of reforming physician payment schemes has been the change from fee-for-service to alternative models. Briefly, fee-for-service is based on physicians being compensated on an established rate for each individual service they provide. Critics of fee-for-service claim that it gives physicians incentive to provide minimum care to an individual patient in order to see more patients in the same amount of time using this theory, the more patients a physician sees the more he/she will be compensated (Mowat, 1997; Ostbye, \& Hunskarr, 1997).

The struggle to transform payment mechanisms has been at the heart of PHC reform (Hutchison, Abelson \& Lavis, 2001; Fooks, 2004; Rachlis, 2006). Relying on their dominant position within healthcare policy and delivery, physicians have been able to set the course according to their own needs.

Reimbursement is also important because it has a direct impact on other elements, such as teamwork, acccss and community action. For example, according to McColl et al. (2006, p. 38): "Provider compensation approaches appear to be at the root of many of the issues impeding integration of allied health professionals in primary care settings." 
As described within Chapter Two, paying physicians premiums, or incentives, for tasks that their non-physician colleagues perform is detrimental to a positive work environment and can also lead to services designed around premiums rather than based on client need (Fooks, 2004).

The models in question are both 'blended' forms of capitation (FHT) and salary (CHC). The blended component is tied to enrolling clients and providing financial incentives based on the care provided to this group of enrolled clients. Incentives are important to chronicity in $\mathrm{PHC}$, as evidence from other countries highlight that "about one-quarter of general practice income is currently derived through the achievement of quality targets in managing chronic diseases such as diabetes and coronary artery disease" (Millett, 2007, p. 6). Evaluation of the implications of this scenario is provided in the next chapter.

Given the importance of reimbursement to quality chronic condition care in PHC, each model will be assessed on two factors. The first, what is the impact of method of payment (capitation or salary) on care for chronicity? The second, how will incentives impact chronic condition care?

\section{Access and Continuity of Care}

Accessibility is important for many reasons. As one of the five principles of the Canada Health Act, it is closely tied to defining the character of Canada through Canadians commitment to Medicare. It also continues to be an important focus of PHC policy making in Canada, as evidenced through papers such as the Health Care Accord of 2003 and the commission on the Future of Health Care in Canada 2002. Accessibility to 
PHC is also the bedrock of quality healthcare, because without it, it is difficult to get coordinated care within the other levels of the system.

At the PHC level, access can be defined in terms of accessibility in time, i.e., the hours of availability, wait times for an appointment, in-office wait, ability to see a provider without an appointment (these are influenced by total client case load per provider); geography (e.g., is transportation adequate to meet distance covered, is the space near to the population it serves); financial access (e.g., is a client forced to forgo earnings to attend an appointment, are their prohibitive ancillary fees such as parking or childcare?) and psychosocial accessibility, defined as language or cultural barriers to communication (Starfield, 1998).

Access is also being redefined. Strategies to increase access include tele-health, or in some cases virtual health care. Moreover, the concept of access (once thought of as access to your family physician) is being replaced with continuity with a team of healthcare providers rather than a primary provider. Consequently, access is often included as a dimension of continuity, and issues of continuity and accessibility are closely entwined (Bachrach, 1993). This redefinition is of particular importance to clients with chronicity, because it directly results in quality of care.

Due to raising concerns about fragmentation of care, policy reports and charters worldwide urge a concerted effort to enhance continuity (Canadian Health Services Research Foundation, 2001). Yet efforts to describe the problem or formulate solutions are complicated by the lack of consensus on the definition of continuity. Continuity of care is also referred to as continuum of care, coordination of care, discharge planning, 
case management, integration of services, and seamless care, which adds to the confusion (Haggerty et al., 2003).

Each model will be evaluated based on the belief that access and continuity of care should not be based on traditional medical model ideology. Primary care and PHC are different, and the benefits derived are different. The first subsection looks more closely at what drives access, and what type of care people with chronic conditions have access to. The second subsection acknowledges that chronicity requires care from multiple providers which can result in a fragmented or duplicated client experience. Therefore, specific attention is paid to how seamless and coordinated the care is and what efforts are in place to avoid fragmented care. This includes the use of an electronic health record.

\section{Governance}

While difficult to rank each criterion, it is fair to suggest that governance plays the largest role in how chronicity is cared for in an organization. This is mainly due to the fact that, within the decision-making authority for the organization, the board of directors and the management ultimately have the power to choose what services are (or are not) provided.

Ontario's Ministry of Health and Long Term Care, in preparing for transition to different models of $\mathrm{PHC}$, has recognized the importance of guiding groups through the concept of governance:

Governance is the way we organize ourselves to do our work, formally or informally, in any social or organizational environment. Governance refers to the authority and responsibility of making decisions and taking action. It is comprised of the structure and processes used to direct or "govern" the affairs of an organization. A governance structure defines the manner in which affairs of an organization are managed and supervised and provides a shared understanding of roles and responsibilities (Ministry of Health and Long Term Care, 2007a, p. 3). 
While the above definition maintains a business-like hierarchical flavour, the following definition as presented by Denis $(2002$, p.3) is more appropriate for this thesis:

Governance relates to the systems and practices that allow agents to develop a plausible perception of their future, to design and implement effective change strategies, and to rely on values that create trust and solidarity.

Governance is of particular concern to this topic due to its link with broader goals and values. Governing each PHC organization in Ontario can be considered a concrete example of how the spirit of the Canada Health Act and other healthcare policy documents are embodied on the ground, specifically in translating ideals and values into programs and services. Values espoused in these documents such as citizen engagement and community governance are believed to have many important benefits for health and health care. Enhanced quality of health care, improved individual and community health outcomes, better accountability, and more efficient use of resources are key dimensions of health and health care where the engagement of citizens can have a positive impact (Patzer, 2006).

Community governance refers to a method of community engagement that ensures effective involvement and empowerment of local community representatives in the planning, direction setting and monitoring of health organizations to meet the health needs and priorities of the populations within local neighbourhood communities (Patzer, 2006). Governance under a medical model ideology is not as inclusive. This is particularly important for chronicity, as care is often dependent on trusting relationships, client empowerment and community engagement rather than cure oriented, acute based service. These values speak loudly to those with chronicity.

The second way in which this element will be assessed is in terms of 'organizational supports.' This component is described by Barbara Starfield (1998) as the mechanisms in 
place to guide directors and management in achieving their objectives. In this case, I will use the provincial associations of the CHC and the FHT as examples of support for directors.

The final component of governance is management and/or leadership. Next to the governance structure in place, leadership is likely the most important criterion in dictating the type and quality of services that are provided. It is powerful in its purpose of ensuring the all other important elements are being considered and achieved. For example, according to the EICP group (as referred to in previous chapters), leadershipboth clinical and administrative-is key to the success of collaborative care (Prada, et al., 2005). This is generally due to the fact that they should have the authority to flatten the traditional hierarchy and introduce an inclusive team based culture into the organization. There are challenges to this, for example a lack of national and provincial leadership, and managers who maintain a medical model perspective. The fact remains that strong leadership is required to ensure inclusion of all other providers in the decision making process. The fact that management is accountable to the executive director, who is in turn accountable to the board, in an environment where each level should have a willingness to ensure inclusion, would be a positive sign.

Governance has the potential to infuse the ideology of true PHC into any organization. Approaches of governing can be viewed on a continuum from least empowered (the ability to be heard) to most empowered (the ability to control the organization) (Starfield, 1998). Each group will determine which governance structure best suits its needs. In the end, the important questions are: How are board members selected? Who is the board accountable to? Are there committees of the board that 
focus on community issues? Who has the authority to makes the decisions? Decision makers have the capacity to implement ideas (good or bad), and breakdown institutional barriers (or not break them down and remain status quo).

\section{Conclusion}

These five components (and subcomponents), cumulatively, provide much insight into the nature of each model, specifically in terms of chronicity. On one level, they demonstrate that health care delivery, chronicity and client outcomes are based on a combination of elements rather than individual parts. There is significant overlap and interaction between different elements, where a change in one factor may face a barrier in

another factor. On another, they provide insight into how agency and power can determine the winners and losers.

As stated, governance holds the most potential for influencing the other elements. Some environments are not conducive to paradigm shifts and therefore require appropriate guidance and leadership to consider other perspectives. The next chapter assesses the capacity of the FHT and the CHC to embrace the benefits of a new way of caring for chronicity in a PHC environment. 


\section{Chapter Four: CHC and FHT - Assessing the Capacity to Care for Chronic Conditions}

The intention of this chapter is to assess two models of PHC in Ontario today, using the framework described in Chapter Three. It is an exciting time of change and opportunity in Ontario PHC. While the traditional structure of primary care organization, funding and delivery has remained intact for years, the repeated calls for policy change have seemingly been heard. This thesis tests this policy decision to determine if the FHT model offers progressive change over traditional primary care delivery, while comparing it to the longstanding $\mathrm{CHC}$ model. The $\mathrm{CHC}$ has been at the margins for years, claiming to offer a different type of care for complex clients like those with chronic conditions. This chapter answers my research question: Is one model better equipped to address the needs of those with chronic health conditions? Moreover, does either model have the capacity and desire to battle historical, structural and attitudinal barriers that have limited the uptake of primary health care?

Each element of the framework is chosen due to its overall importance in delivering quality health care, and will be assessed according to its influence on the nature of care that will be delivered for people with chronic health conditions. Each element has been divided into subsections which help penetrate the topic. For instance, as reviewed in the previous chapter, the elements of this framework consist of:

- Community Action and Supportive Environment - assessed by ability to included health promotion activities as well as conduct community work;

- Teamwork - assessed by ability to value roles beyond medicine and also include the client as part of the team;

- Reimbursement - assessed by looking specifically at physician payment schemes and also the impact of financial incentives on care delivery;

- Access and Continuity - assessed by considering what type of services clients have access to, and also what efforts are in place to improve continuity of care, including the electronic health record; 
- Governance - assessed by considering the level of community responsiveness, organizational supports and the ability of managers and leaders to foster positive change.

Given the recent introduction of Family Health Teams, there is essentially no published literature on their performance, making comment on them, let alone comparisons, unsubstantiated. This is not an empirical study and should be treated as being theoretical. That said, the objective is to take what is known about the nature of the organization(s) and apply theory to the pertinent points. The purpose is to highlight areas of opportunity and also concern in how each approaches chronic care. We can also extrapolate based on the fact that the governance model of the FHT is classified as a 'provider coordinated model.' By definition, this excludes community involvement, and for the most part, excludes non-physician providers. Therefore, in some ways the experiences of the Health Service Organization model (in Ontario) and the Health Maintenance Organization model (in the United States), both provider coordinated models with similar payment schemes, are pertinent to the debate. In other ways, such as the fact that FHTs are physician-run while HMOs are investor-run, comparisons are not useful and even erroneous. While there are useful examples that can inform how a FHT may function, the differences must be acknowledged. 


\section{Element 1 - COMMUNITY ACTION AND SUPPORTIVE ENVIRONMENTS}

As explained in Chapter Three, this element is drawn directly from the Ottawa Charter of Health Promotion, 1986. Its purpose here is to highlight the importance of health promotion and community work, in an effort to challenge the traditional power imbalance between medical and non-medical determinants of health. It will be assessed first by analyzing the resources each PHC model assigns to health promotion activities, and secondly by looking more closely at how services are aligned to meet the needs of the community.

\section{Health Promotion Activities}

\section{Community Health Centre}

Perhaps the biggest factor that separates CHCs from other models is their rich history of health promotion activities (Patzer, 2006). This is generally accomplished at three levels; first at the individual clinic level, where preventative care is a focus. Examples include age appropriate screening, proper diet, substance use, support system, and safety at home. The second level is group programming, implemented through variety of community health oriented staff such as Health Promoters, Volunteer Coordinators, Early Years Social Workers, and Community Development Workers. This component of the CHC is significant, as the people in these roles are trained to address causal circumstances. Despite their best intentions, most medical staff are not trained and do not have the time or the know-how to practice health promotion in this way. The final level is the community initiative, which is described within the second subsection (community work) below. 
CHCs may assist clients to develop community kitchens, community gardens, cooking workshops, bulk food purchases and education sessions for low-income families. In some cases, CHCs may partner with other agencies so that staff from one or more agencies may work together in an integrated fashion in one location. These programs offer considerable health benefits.

CHCs also provide a mechanism for clients to access other health and social service agencies such as housing, addiction services, specialists, child development and family home visiting. If possible, $\mathrm{CHCs}$ attempt to co-locate with these types of services to facilitate the referral of clients. In the end, this means that model places an importance on health promotion activities. This has not been the case in traditional medical model ideology. The result of prioritizing health promotion is a more holistic approach to care for clients.

\section{Family Health Team}

FHTs have a great opportunity to act on the health promotion literature. Many already have allied health providers employed, normally dietitians and social workers, who are available for referral. Many of the physicians and nurse practitioners will work in a manner where health education is done through the NP, thereby ensuring the physician has time to see the more complicated clients.

However, looking at the experiences of the HSO and HMO, both funded in the same manner, there is often a conflict with time demands for providers to pursue true health promotion. This contrasts somewhat with CHCs, where as described, health promotion is often given a priority or equal footing with clinical, acute tasks. FHTs have special 
opportunities to provide health promotion work, but the personnel will need to take a leap of faith and maintain strong leadership to make change happen.

The perspective or ideology of the providers in this model is also important, and will dictate how much faith they have in health promotion work. As presented, the Ministry of Health and Long Term Care has packaged the FHT model as offering enhanced efficiency; increased access; improved quality of life for providers; reduced costs for the state. How providers are paid (which is assessed in this thesis within the Reimbursement element) is also of concern. The point here is that these objectives of PHC reform, and the intentions of the physicians who work within the FHT model, can present a conflict with demands for true health promotion activities and can influence the care provided. In an era of 'accountability', where all models of PHC may be put in a pseudo competition and compared next to medical model indicators, a genuine prioritizing of health promotion work will be necessary.

Health promotion requires appropriate needs assessments and educational diagnoses to match the program intervention to the target population (Wilner, 1986). Often this work is less quantifiable or 'curable', and presents a conflict with time demands. In reviewing the approaches HMOs have taken in defining their priorities and health promotion policies, most have adopted a very traditional model. For instance, the typical HMO offers a wide array of group programs or services dealing with smoking cessation, exercise, nutrition, stress management, weight reduction, and low back pain prevention (ibid). Programs and services that address the social determinants of health are more infrequent. 
In summary, FHTs have potential given that with an enrolled population and special incentives, they could be offering extremely innovative programs and services. These incentives, while still based on medical model ideology, offer some opportunity to progressively change the way $\mathrm{PHC}$ is delivered. A primary barrier to their integration is the continued skepticism about the cost-effectiveness of health promotion activities. The emergence of health promotion activities is likely to derive more from belief than from evidence. As the concept of healthcare provider is being pushed beyond the physician to include the team and even the system, embracing health promotion is both an opportunity and a challenge.

\section{Community Work}

\section{Community Health Centre}

CHCs base all programs and services within a geographic catchment area, and are therefore able to claim a defined community. Community initiatives are a lively part of all CHCs. Described as programs that improve the health of the community (rather than targeted at individuals or groups), they are varied and vast. Examples of issues addressed by community initiatives that address or assist chronicity include weekly bike repair clinics, indoor air quality, recreation spaces and improved use of park spaces. They normally include spearheading an issue, bringing community members in to the mix, then addressing it and making appropriate changes. They often result in concrete change in shared environments (e.g., improving local bike lanes) or change in personal behaviours (e.g., the safer use of cleaning products).

An example of a successful community initiative is community gardening. Gardening is Canada's second most popular physical activity after walking. Gardening 
delivers a breadth of benefits, such as physical activity, emotional expression, mental and physical healing, stress reduction, and lowered blood pressure. The Public Health Agency of Canada (2007) cites horticultural therapists who claim gardening stimulates the senses, especially for older adults. Different sights, sounds, textures and scents arouse feelings and memories from the past. Gardeners also tend to be more optimistic and find life more satisfying than non-gardeners.

The community aspect encourages interaction, where people learn to feel comfortable talking to each other because of the garden. The garden creates opportunities to talk something very simple, but also very therapeutic to chronicity. Other benefits include: affordable food for their families; reduced noise pollution and temperature, development of a sense of belonging and the breaking down of barriers of isolation (Public Health Agency of Canada, 2007). These are needed benefits to someone dealing with a chronic condition. Community Health Centres are in a unique position to respond to local issues and provide expertise, stability and resources.

\section{Family Health Team}

Do FHTs have a defined community? According to Gofin and Gofin (2005), 'community' has five distinct definitions, listed in order of preference: (1) a true community in the sociological sense; (2) a defined neighborhood; (3) workers in a factory or company or students in a defined school; (4) persons registered as potential users of a group practice, a health maintenance organization, a neighborhood health center, or other defined service; and (5) users of a defined service or repeated users of the service. By this definition, most FHTs fall within level four and five. This poses a problem because 
these organizations may not feel connected to, or directed by, the community. This is an important distinction from the $\mathrm{CHC}$ model which is responsive to community needs.

FHTs.might work with the local non-medical infrastructure or work to shift public priorities to address underlying causes of disease. One advantage would be links to businesses that may not be willing to work with $\mathrm{CHCs}$ due to a reputation of an at-risk population that they do not want to be aligned with. FHTs may be more mainstream and therefore a better investment for businesses, leading to opportunities for community work.

Community development requires a substantial time commitment. As time and resources are in competition, and due to the fact that community development is a longterm investment, FHT providers will mostly maintain an individual focus. HMO research supports this, suggesting that their willingness to pursue community activities might be affected by their legal governance structure (Schlesinger, 2004). The return on community work is normally not realized immediately. Another consideration is the ability to finance community benefit initiatives when the focus is on protecting individuals enrolled (ibid). I hypothesize that this regulation diverts resources away from community-oriented activities. In contrast, CHCs employee community development workers who specialize in this area.

\section{Element 2 - TEAMWORK}

Teamwork will be assessed in two ways. First, the value each model puts on multidisciplinary roles, and second, the ability of each model to include the client as part of the team. This assessment involves the ability to break down structural, historical and attitudinal barriers of the medical model hierarchy. Valuing multidisciplinary roles looks 
specifically at how physicians embrace non-physician providers such as the nurse practitioner (NP). The NP is a good example because it is the main role that collaborates with physicians, and also shares an overlapping scope of practice. This piece also addresses how teams share decision-making authority and how teams choose a leader. The second level of assessment, valuing the client, is assessed by the ability of providers to embrace self-management techniques, including breaking down traditional hierarchical patient/doctor relationship and move towards a more egalitarian relationship.

Value Multidisciplinary Roles

\section{Community Health Centre}

Most CHCs employ physicians, nurse practitioners, nurses, health promoters and most CHCs also have social workers, counselors, and dietitians. Some CHCs also employ respiratory therapists, physiotherapists and occupational therapists who can be involved in research studies, creating individual care plans, and group programming (McColl et at., 2006). Case managers from Community Care Access Centres are also sometimes located within CHCs (Hoffman \& Dupont, 1992). The CHC structure (salaried employees, time for team meetings, etc.) encourages team based attention and planning around major chronic conditions. The structure also supports decisions by consensus in a non-hierarchical fashion. When there are differences of opinion or conflicts, a clinical manager normally has the final word.

The main benefit, which is not universal across all CHCs, is the perspective from which the physicians view teamwork. In this case, it is based on a belief that the basis for shifting to multidisciplinary teams is because it improves care. An additional positive is the longevity of these organizations. More than 30 years experience in multidisciplinary 
practice is evidence that it is working. Additionally, many CHCs are very advanced in working as a team due to this longevity. That said, teamwork is not a given and is not universal across all CHCs.

The value placed on the nurse practitioner role is a good example of how CHCs value multidisciplinary teamwork. CHCs are the main employer of NPs in the province, and are often training facilities for NP students. A recent Ontario Health Quality Council report indicated that $\mathrm{CHCs}$ provide superior chronic illness care, compared to other $\mathrm{PHC}$ models in the province (Ontario Health Quality Council Report, 2008). The study points to the appropriate use of NPs as the major reason for the difference in outcomes.

There are also two main challenges I have identified which have not been addressed to this point. The first deals with the challenges of sharing a scope of practice with a physician. This sharing and overlapping can result in conflict, mainly because 'sharing' is still a relatively new concept to physicians. On the other hand, many nurse practitioners who desire to have an autonomous practice, are at the same time asking their physician colleagues 'to give up control' of their client load. This is a conflicting message, and despite literature supporting the co-existence of autonomy and collaboration (Bailey, Jones \& Way, 2006), it is confusing how this works in real practice.

The fact that nurse practitioners have often not been able to detail exactly what they want (they have been effective in presenting what they do not want) has also been a part of the struggle. The evolution of a nursing role has not always been welcomed within nursing (American Nurses Association, 2006), and this evolution is limited by the inability of some nurses to embrace new ideology or discard traditional medical 
dominance. This is expressed in the main by traditional nurses who worked well within a hierarchy and do not deal well with changes that alter traditional team dynamics. Above said, many challenges and conflicts that can occur within this setting occur due to honest efforts to collaborate and change. The environment of shifting to a more egalitarian approach should result in constructive dialogue and even sometimes conflict.

Secondly, while much of the literature on collaboration highlights the barriers posed by physicians, more attention should be paid to other staff members who a) have an overly strong anti-medical model attitude that in itself prevents any form of effective collaboration; or b) are unable or unwilling to appreciate the distinct differences in the nature of the clinical and non-clinical jobs, and expect complete consistency. People should accept that regardless of the model, clinician time is in high demand. Their day is most often set for them by someone else (a medical secretary) and they are at the mercy of this schedule. Given the multi-factorial needs of people with chronicity, often time is an issue.

Partly due to structures and partly due to necessity, in order to create positive change in a team working environment, both physicians and non-physicians need to maintain a flexible attitude. This means that some individuals must be more open to new ideas, and others who should do away with preconceptions.

\section{Family Health Team}

Most of the existing literature on teamwork addresses the physician and nurse practitioner relationship, and little exists on how physicians value other allied health care providers. In the FHT model, the ideological belief on the basis for a shift to teams may be different than that of the CHC. If one can assume that the FHT physicians are more 
closely aligned to a traditional medical model ideology, one should be concerned with the value they see in other providers. OMA literature is straightforward on this topic (see Appendix B). This is a critical point of the thesis - is the PHC model able to break down the remnants of the medical model? If the belief is that the main impetus to create multidisciplinary teams was to reduce costs, then status quo acute-based care will be more difficult to change. A sincere belief that multidisciplinary teams offer improved quality of care is of particular importance to clients with chronicity, as their care is enhanced by non-physician providers (Clark, 2003).

An advantage of many of the FHTs is their relationship or partnerships with pharmacists. While the inclusion of pharmacists in PHC is low overall, this model may have better opportunity to forge relationships. Medication management is particularly important for vulnerable people dealing with chronicity. The frail, the elderly and those with learning difficulties or mental health problems are particularly prone to poor medicines management. That said, pharmacists have a more traditional role within PHC, and because their scope of practice does not infringe on medicine in the same way a nurse practitioner does, they maintain a more comfortable relationship with physicians. Therefore, this relationship has not changed substantially in the shift to multidisciplinary teams.

The overregulation of NPs (at the behest of physicians) is a major factor in why the system has been unable to capitalize on the potential contributions of these providers. According to a recent Nurse Practitioners Association of Ontario document (2005, p.3), there is much concern over how teams will function in the FHTs:

If the Family Health Team model is to be effective in meeting the objectives of the Health Care Accord, and notwithstanding the key role of family physicians in primary health care, it is imperative that Nurse Practitioners are recognized as essential members 
of the health care team. A shift in power and decision-making from a physician dominant structure to one that is more egalitarian and democratic is necessary to achieve this objective.

This quote demonstrates the concern not only over the division of labour in PHC, but also over the structures and attitudes of traditional medical model ideology.

\section{Client as part of Team}

\section{Community Health Centre}

I argue that thanks to a consistent CHC value of broad health promotion concepts among the health care providers, there is a smoothed path to embrace the client as part of the team. In fact, egalitarian relationships are part of health promotion philosophy (Frankish, 2006). This is especially important when considering a person with a chronic condition. Upon diagnosis, people often go through denial and fear before engaging in a trusting relationship with their provider, and trust is realized only when clients know providers care about the whole person (Bodenheimer et al., 2002a).

Building on the previous nurse practitioner example, the training and scope of practice of the NP includes many of the patient self-management philosophies, such as goal setting, engagement and empowerment. Self-management is a critical component of

the Chronic Disease Prevention and Management framework (see Appendix D), and virtually all CHCs are engaged in delivery of these programs. Self-management programs are serving as a long-awaited 'bridge' of collaboration between clinical staff and health promotion/community work staff because they achieve goals of clinicians, community staff and clients.

\section{Family Health Team}

Some FHTs have started offering self-management group programming. In my view, egalitarian client/provider relationships involve a considerable paradigm shift away from 
the medical model, and the quest to change patterns of practice may be more difficult in the FHT model. Consequently, these groups may be less of an importance as they are in the CHC setting.

\section{Element 3-REIMBURSEMENT}

Accepting that there is no ideal method of remuneration, each model will be assessed on its method of physician payment, i.e., salary or capitation. This is accomplished first by evaluating each payment mechanism, and secondly by evaluating the role that incentives will play in influencing care for the chronically ill. When incentives are combined with another form of reimbursement, it is labeled 'blended' (Monrad, 1995).

\section{Method of payment}

\section{Community Health Centre}

CHC physicians are paid a blended salary. There are at least three advantages associated with a salary payment scheme. First, it provides more predictable physician expenditures. The expenditure on physician payment is determined by the salary rate per physician and the number of physicians. These two elements are within the scope of government control. Second, it eliminates the possibility of 'cherry-picking' (where there is a preference for healthy clients who require fewer services) under capitation and biased selection under fee-for-service, since physicians on salary are paid the same contract amount regardless of the size and health status of patients' population. This should lead to more equitable access to health care, in that the physician is making the same income regardless of the health status of clients (particularly important for chronic condition clients). Third, it removes many of the time pressures that physicians in other models feel. Physicians almost always have more time with clients compared to other 
models, and are encouraged to address the non-medical determinants of health when appropriate. This is also of great benefit to those with chronicity who have complicated medication regimes and multi-factorial issues.

On the other hand, there are generally two main issues with salary payment. First, lack of effort to do more is based on empirical studies showing that the service volume provided by salaried physicians is consistently lower than that by fee-for-service physicians (Mowat, 1997; Ostbye, \& Hunskaar, 1997). In one way this is a negative in that there are fewer service events, yet it is merely a count and does not shed light into the quality of these visits. This is typical of quantitative objectives that are concerned only with a number. The second issue with salary is potential for poor continuity of care. Given that salary payments are not linked to a patient population, in theory physicians have little incentive to maintain a stable patient population.

\section{Family Health Team}

FHT physicians are paid blended capitation. In capitation funding, clients receive services from physicians on whose list they are placed and physicians receive a flat fee for each patient on their lists (adjusted for age, sex and some conditions). This is regardless of how much or how little care is provided (Booth, Sapp \& Ferguson, 1996). Benefits of capitation funding in Ontario are described as follows: First, since physician expenditures are determined primarily by the level of capitation fee and the size of the resident population, control of physician expenditures requires only control of the level of capitation fee. This formula also reflects the reality that capitation payments allow health resources to be allocated on the basis of population size rather than physician activity. Second, the literature shows that capitation has the potential to encourage physicians to 
communicate and cooperate with other health care providers to provide the best practices based on clinical evidence (ibid). Third, since the loss of a dissatisfied patient to another physician can lead to the loss of income under capitation, the competition for patients should generate a strong incentive to promote and maintain a better relationship between a physician and his/her patients. Moreover, since physicians under capitation maintain a relatively stable patient base, they tend to provide good continued-care for their patients (ibid).

On the other hand, there are also problems associated with capitation. First, capitation eliminates the incentive to over-service, but it may lead to the other extreme, i.e., to provide fewer services than the population's real need. Grignon, Paris \& Polton (2002) point out that:

\begin{abstract}
While lump sum payments offer a structural means of resolving the problem of increased volumes of services delivered by physicians, it raises the risk that the physician will provide too few services and too few non-material resources (shorter consultations, less attention) to the patient. ...If the physician is paid to manage a patient and is not sanctioned in any way, he has an incentive to collect the lump sum payment and not provide the corresponding services and effort (p. 13).
\end{abstract}

Second, Grignon et al. (2002) argue that physicians under capitation have incentives to transfer their own work to others by referrals and to increase the volume of prescriptions so as to cut down on unremunerated effort. This argument is supported by several empirical studies (Bodenheimer \& Grumbach, 1996; Hurley et al., 1999; Mulligan, 2002).

Third, capitation encourages physicians to choose their clients based on health status. They tend to select only patients with less health service demand, and avoid those who require more time-intensive care. This 'cherry picking' is one of the major problems associated with capitation (Gillett et al., 2001). One possible solution is to increase the capitation fee for the population that demand more health care. 
In summary, under capitation the payment scheme may be associated with a lower cost, but its impact on health care quality is uncertain. Capitation builds on FFS, specifically in the ability to maintain a degree of independence in professional practice (College of Family Physicians of Canada, 2007). This funding arrangement is an example of how the medical model persists within the FHT model. This payment mechanism was introduced not to improve client outcomes, but rather to appease physician demands and align with the cost reducing priorities of the state.

\section{Incentives}

\section{Community Health Centre}

This issue sheds light on how a power imbalance is affecting not only reimbursement, but teamwork as well. The importance of enrolling (or rostering) to a group or team rather than individual physicians has been argued since its inception with the Health Service Organization model over 30 years ago (Gillett et al., 2001). With the resurgence of this payment model, the debate is once again alive. However, the Ministry has once again decided to limit rostering to only physicians, not the team, irrespective of the model of PHC. The terms of this agreement were part of a bilateral agreement negotiated between the OMA and the MOHLTC and did not include other providers who will in fact be doing much of the work that this agreement is based on. (It is out of control of the $\mathrm{CHC}$, but can have a considerable impact on the functioning of the team. While this above example does not directly compare the two models in question, it touches both and therefore we must consider the impact on each.)

There are two main messages of this arrangement. It is contradictory to the philosophy of comprehensive care within a collaborative interdisciplinary team model. It 
maintains the misguided perception that the physician is responsible for all aspects of client care. It erases the work of all team members except the physician, as there is no mechanism to collect data that reflects the role of others, such as the nurse practitioner, as a primary care provider.

Secondly, considering incentive payments, the decision by the Ministry to remunerate physicians for the work done by others has had a particularly negative impact on the nurse practitioners, including devaluation of their work, and the potential for their scope of practice limited to only premium/incentive activities because their physician partners benefit from this activity. The major point here is that incentive payments are destructive to a collaborative model of care. To have one provider paid an incentive for work performed by another provider is simply a step backwards that threatens the very theory that we have been pursuing for close to 40 years.

\section{Family Health Team}

This argument is best captured by the notion of the intensity of incentives. Incentive intensity describes the degree to which clinical decisions are influenced by physician payment schemes; more intense incentives have greater effects on physician behavior (Pereira \& Pearson, 2001).

Also, the use of financial incentives to reduce health care costs is of concern to many in the fields of law, medical ethics and public policy (Hall, Dugan, Balkrishnan, \& Bradley, 2002) because it may impact decisions on care. The secondary impacts of these incentives include practice design based on financial incentives rather than client need. These incentives do little to encourage collaborative treatment and coordinated care. Current literature and public opinion value teamwork, integration, and prevention (in the 
social determinants of heath sense), yet incentives do not account for that. Importantly, clients are often uncomfortable with the notion of incentives (Pereira \& Pearson, 2001).

One should be concerned with what we can witness in the U.S. HMOs. The next step of being paid financial incentives for services rendered is being paid financial incentives for services not rendered (i.e., keeping costs low). In the HMO model, the discontent of many physicians is attributable to frustrations in their attempts to deliver ideal care, restrictions on their personal time, financial incentives that strain their professional principles, and loss of control over their clinical decisions (Kassirer, 1998). Based on the above factors, I conclude that the intensity of incentives are stronger within the FHT model.

\section{Element 4 - ACCESS AND CONTINUITY OF CARE}

As described in Chapter Three, access and continuity of care are important because in many ways, they determine the overall client experience. Whether or not a person with a chronic health condition has access is profoundly meaningful, as needs and issues are magnified, and thus the ability to see a health care provider in a timely fashion is critical. Without adequate access, their condition may deteriorate and they will also have a difficult time connecting to other parts of the health care system. In the same way, continuity of care is critical at the primary level, and also between levels of the health care system.

\section{Access}

\section{Community Health Centre}

CHC prides itself on being accessible. Programs and services respond directly to individual and community needs. They are able to claim this because of annual Client 
Satisfaction Surveys, and more elaborate Community Needs Assessments which are conducted every three to five years. CHCs claim they help eliminate barriers for people who have complex needs. They might be seniors, aboriginals, immigrants, homeless people, the mentally ill, youth and others. CHCs strive to meet immediate health needs and prevent more expensive care later (Tanner, 1999).

Critics of the CHC model normally address inefficiency first (Devlin, Sarma \& Hogg 2006), which would equate to limited access. This is a medical model assumption, in that efficiency is praised without adequate attention to the consequences of efficiency, or the short cuts that are sometimes taken in the name of efficiency. The usual counterargument to inefficiency is that $\mathrm{CHCs}$ provide high quality PHC, taking appropriate time to assess the whole person and dealing with multiple issues in one visit. Furthermore, the prevention, health promotion and community development philosophy encourages adequate time in these areas.

In terms of increasing access, if CHC physicians are more philosophically aligned with teamwork, this should result in appropriate use of the full team, thereby becoming more efficient and reaching more people. While reasonable to suggest that $\mathrm{CHCs}$ (or any model) could improve efficiency, it should not be done without proper attention to the needs of complex clients and the time it takes to care for them. In the context of chronicity, these clients need ongoing attention.

\section{Family Health Team}

If FHT physicians and other providers are interested in financial incentives, these incentives may result in better access due to the desire to increase volume. Yet payment by capitation has also been shown to provide an unintended incentive to avoid the most 
severely ill patients, thereby restricting access to care for this group. This is termed adverse selection (Bloom et al., 2002). In the context of chronicity this would pose a serious problem.

In most cases, FHT providers will have a larger client load compared to the CHC. So in these ways, more clients may have access to a physician or team. In the end, access should be measured against quality of care and wait times for appointments.

Assessed in a different way, if FHT physicians are unwilling to let go of the sole/main provider role and are hence forced to see too many clients themselves, this in effect limits the overall number of clients a team can take on. FHTs may be more efficient, but if they are unwilling to divide clients among team members, they ultimately provide care to fewer clients. Additionally, lack of trust within the team can result in inefficiency as the physician will want to confirm or double check the clients whom the NP has seen.

There is potential for innovative providers (a more corporate, business minded philosophy is often equated with entrepreneurial and therefore innovative) which may allow more openness to trying new ways of doing things (group appointments, etc.) that in turn could improve access. Yet again, the alternative argument is that most of these physicians have transitioned into the models where innovation was not occurring and therefore we can not expect it to happen within a FHT.

\section{Continuity of Care}

\section{Community Health Centre}

Due to the $\mathrm{CHC}$ reliance on a multidisciplinary health care team, $\mathrm{CHC}$ clients could be more apt to see multiple providers compared to elsewhere. In addition, the literature highlights that because salary payments are not linked to patient population, physicians 
have little incentive to maintain a stable patient population (Ostbye \& Hunskaar, 1997). These examples pose a problem on the continuity of care for patients, and could result in less continuity of care. According to Schoen et al. (2004, p. 493), "There are serious safety consequences of poor continuity. Improving coordination and continuity of care are key goals of primary care initiatives. Failure to coordinate care across sites of care or capture episodes of care in patients' medical histories can lead to medical errors, undermine quality and outcomes, increase duplication and other inefficiencies, and frustrate and overwhelm patients."

One of the key recognized strategies for improving continuity of care within a team environment is the Electronic Health Record. CHCs, while in one way hold an advantage due to a common system across the province, are forced to deal with a mediocre software system. This results in slow uptake of the system by health care providers, but eventual benefits to the client.

Another strategy that CHCs employ to improve continuity is the Practical Assistance Worker, who acts as navigators of the system. This improves continuity of care, and aids in an area which is a big source of frustration for clients. Clients with chronic conditions are heavy users of the practical assistance worker.

\section{Family Health Team}

Two main points stand out in for the FHT in this section. Firstly, given that FHT physicians may be unwilling to let go of the sole/main provider role (because of an attachment to the medical model ideology), this would in effect maintain good continuity of care (more traditional patient-physician relationship). Secondly, the electronic health record is critical to continuity in a team environment. FHTs are in a good position in this 
area, because the Ministry of Health and Long Term Care is funding systems to support their conversion from paper charting to electronic charting (Ministry of Health and Long Term Care, 2007c). This enables each team to choose the system that best suites its current work flow and their desired changes.

\section{Element 5-GOVERNANCF}

The final element of the framework, governance, will be assessed in three ways: First, through close attention to how inclusive or responsive the governance structure is to the community, and what this means to caring for people with chronic health conditions. Second, by looking at what organizational supports are in place to ensure policies and practices address the needs of those with chronicity; and third, who manages and makes decisions in each team of health care providers, and what are the implications of each scenario.

\section{Community Responsiveness}

\section{Community Health Centre}

CHCs are governed by not-for-profit community boards selected from the communities they serve. Board members are independent community-minded individuals and generally reflect the community they serve. These boards are accountable to the Ministry of Health and Long Term Care, and are expected to ensure that services and programs offered to the community are relevant and appropriate.

Boards usually consist of 9 to 14 members, and each member is elected annually and usually serve up to 3 years (Hoffman \& Dupont, 1992). (See Appendix E for an example of Ontario CHC board of directors list). An Executive Director who is hired by and 
accountable to the Board manages each $\mathrm{CHC}$. There is often a middle management team as well, each responsible for a particular group of staff (e.g., clinic manager, community health manager, finance and administrative manager) who work under the executive director (ibid).

Boards normally work through a number of working groups and/or advisory committees typical of not-for-profit organizations. Examples of these committees include Public Policy and Social Action Committee, Joint Planning Committee, Board Affairs Committee, and Finance Committee.

Additionally, $\mathrm{CHC}$ boards create the strategic plan for the organization, thereby influencing all programs and services of the organization. The accreditation process that $\mathrm{CHCs}$ are subject to ensures that each organization has a system to evaluate that the strategic plan laid out by the board is translated into programs and services. The strategic plan is guided by the results of community needs assessments and client satisfaction surveys.

One of the primary purposes of a community board is to remove decision making power from the hands of physicians and place it with the board and the executive director (who is directly accountable to the board). This is an example of how the values espoused in health care policy documents are translated into policy.

According to a recent study of this topic, citizens who are participants in decision making processes of their PHC organization feel that their participation leads to improved programs and services, and to a more responsive range of programs and services that meet the needs of the community (Patzer, 2006). 
In addition, $\mathrm{CHCs}$ are seen as "organizations that increase community capacity through helping communities and individuals raise awareness about health and social issues, identify community strengths and weaknesses, build shared community values, increase community and individual confidence to participate, and increase levels of trust within the community" (Patzer, 2006, p. 15). Individual capacity is enhanced through board membership and volunteerism in turn flows back into the community. Client satisfaction surveys and other evaluation of programs and services offered at CHCs across the province prove the model makes differences as cited above. The $\mathrm{CHC}$ model has been criticized for a lack of outcome-based data (Mathews \& Lockhart, 2003). While a push for data is a medical model objective that should be assessed with a critical eye, the criticism is justifiable because $\mathrm{CHCs}$ have traditionally been unable to provide evidence to support the claim they provide quality health care.

\section{Family Health Team}

According to the Ministry of Health and Long Term Care (2007a), flexibility and choice constitute a guiding principle for Family Health Teams. This is evidenced by the options available for governance. FHTs have a choice of three governance models, including: 1) Non-profit community groups with a board of directors comprised of community representatives (e.g. community health centres, hospitals); 2) Provider groups who are partnerships, corporations or professional associations; 3) A combination of provider and non-profit community groups.

Within a provider-based model there are options for partnerships, professional corporations (for professions governed by the Regulated Health Professions Act) or individual providers contracting together through a contract of association. Provider- 
based models may or may not choose to establish an executive team to govern. Providers may also establish non-profit corporations, which are governed by a board of directors, subject to compliance with existing applicable legislation. Provider groups may also consider the option of establishing a community advisory board to provide advice as needed. Or they may choose not to. Despite the choices available, the majority $(\sim 85$ percent) of the FHTs in Ontario to date are provider-based FHTs (Ministry of Health and Long Term Care, 2008). It is important to note that this version is the focus here.

According to the Ministry of Health and Long Term Care, teams will have an obligation to ensure that all health care disciplines involved in a FHT have a voice in its operation and that the FHT as a whole is responsive to the health needs of its local community (Ministry of Health and Long Term Care, 2007a). However, there seems to be no way to monitor the above obligation, and more importantly, there is no obligation to ensure provider based FHTs are giving the community a voice. The only link to community involvement is found in the description of provider based FHTs: "Provider groups may consider the option of establishing a community advisory board to provide advice as needed" (ibid, p. 4). This lack of involvement is troubling, given the importance of community engagement to one's health status. A study conducted in New Zealand compared community-governed non-profit and for-profit primary care practices. Differences found between these two types of primary health care organizations were associated with their ownership and governance arrangements. Community-governed non-profits were more likely to have quality management policies and to carry out local service planning and community needs assessments. They also had policies and practices in place that reduced financial and cultural barriers to access of services (as quoted in 
Patzer, 2006). (See Appendix F for an example list of a board of directors for a FHT in Ontario.)

Given the early stage of most FHTs, and their inward priority of establishing the teams themselves, published information is not available. Therefore, I have relied mostly on government documents from the Ministry of Health and Long Term Care. Other information such as how board members are elected, or how new members join is not available at this time.

According to legal advice for physicians considering FHT, the arrangement is more about suiting the needs of physicians rather than community health needs:

\begin{abstract}
Suffice it to say that when all is said and done, each FHT has considerable flexibility to structure its arrangements as it sees fit. We believe the best approach for you to take is not to get hung up on the academic/theoretical question of the practical and policy implications of the three governance models, as described by the Ministry. Instead, you should consider and determine what is your desired result. The available governance models, legal vehicles and governance frameworks can be manipulated and developed in a multitude of ways (through various combinations and configurations) to get to your desired outcome (Scott \& Quigley, 2007, par. 6).
\end{abstract}

\title{
Organizational Supports
}

\section{Community Health Centre}

The Association of Ontario Health Centres offers a comprehensive series of educational sessions for board members and staff. Board topics include governance, accountability, performance appraisals and strategic planning, while staff topics include collaborative teamwork, program planning and evaluation.

In my estimation, there is excellent attention paid to the root causes of illness within this model. Community programming, political advocacy are engrained in the culture of the organization. Most CHCs are long-standing, or satellites of long-standing boards which allows for ongoing growth and community understanding. 


\section{Family Health Team}

The discourse on the Association of Family Health Teams website is very telling. The "Information for Health Providers" page reveals that it is heavily medical model based (see example in Appendix G). The information is almost exclusively based on income and liability. For example, topics such as income stabilization and primary care payments are combined with liability and metrics. As has been presented, the attention to payment in this model seems to dominate at the expense of other priorities. Additionally, the links to Social Work and Occupational Therapy contain no information at all. This provides insight into some of the cautions for this model.

The section of the Ministry of Health and Long Term Care website that is dedicated for FHTs and interested parties is equally telling. Paying no attention to documents created exclusively for funding purposes (e.g., information that details funding opportunities, business plans, etc.), the more promising health promotion guiding documents are concerning. For example, the module on community partnerships is titled 'Guide to Community Funding Partnerships and Program/Service Integration' (italics added). Similarly the guide to health promotion and disease prevention contains a prominent section on funding assistance. Again, and most pertinent here, the 'Chronic Disease Management and Prevention' guide contains the same funding element. FHT application material is on enterprises with 'business plans', 'business strategies' intended to maximize profit (Ministry of Health and Long Term Care, 2007b). A prime example is the discourse of the application to become a FHT - A Business Plan must be submitted, justifying in terms of efficiency and effectiveness. This type of discourse is of concern because it highlights the business/finance priorities of this model. 


\section{Management/Leadership}

\section{Community Health Centre}

Management's commitment to, and understanding of, health promotion is often a first vital step in developing an organization wide approach to accepting health promotion, and thereby indicates a commitment to addressing the root causes and non-medical components of chronicity. The most effective champions are often those in mid-upper management positions with a sense of leadership, motivation, compromise and appropriate negotiation skills (Frankish et al., 2000). Management has the potential to foster teamwork through staff performance appraisals.

Management also plays a large role in translating the consequences, impact and future of decisions that have been made at the Ministry of Health and Long Term Care level. This is important because interpreting these decisions often provides considerable latitude. For example, consider the decision to enroll clients only to physicians rather than to the team. While all power is clearly in the hands of the Ministry of Health and Long Term Care (with significant OMA input), and therefore an issue managers cannot change, how this is considered and communicated by management to the team is important. What is required is acknowledgment of the serious weaknesses in this decision, an understanding voice to the non-physician team members, and a clear teambased strategy for dealing with a situation that is at odds with the team based literature as presented in Chapter One. Alternatively, accepting the Ministry decision at face value, with no open dialogue around the concerns and consequences, can lead to team issues between professions which ultimately could impact client care. There are CHCs in Ontario that have refused to enroll a single client based on principle. This required a 
culture of trust and equity and a common belief among all staff that it was wrong, a situation that was eased by strong leadership. These decisions test the values of an organization on an ongoing basis. The values will be tested many times and put under stress due to growth and change.

\section{Family Health Team}

The opportunities in this area lie in the sheer number of providers, and therefore clients, that improved systems would touch. For instance, strong management will have the ability to facilitate changes away from traditional ways of thinking and as a result impact the lives of many people with chronic conditions.

There are two considerations for management within this model. First is the concern that managers are hired by, and accountable to, the board of directors. In the case of a provider-led model, it is unlikely the managers will have the ability to make meaningful changes if they are not in line with physician interests. The lack of authority for managers can keep the status quo in tact.

Secondly, setting priorities for well-planned and well-managed health promotion initiatives is critical. The typical management challenge of allocating scarce resources to competing priorities may be skewed by the medical model ideology of providers and practices.

\section{Conclusion}

This chapter has illuminated the similarities and the distinct differences between two major models of PHC in Ontario. The framework was designed to allow assessment of how each model resembles a holistic definition of health as it applies to chronic condition care. 
In summary, the Community Action and Supportive Environment element demonstrated why health promotion and community work is so important to the health status of those with a chronic condition. It highlighted that $\mathrm{CHCs}$ are more philosophically attached to health promotion concepts, leading to a fuller commitment to embed health promotion in health care delivery. This section also presented that there is a stronger emphasis on community work within the $\mathrm{CHC}$ model.

The Teamwork element suggested that the value physicians place on allied healthcare, and also their ability to include the client as part of the team has a great impact on the outcome of care for clients, especially those dealing with a chronic health condition. CHCs were positioned ahead of FHTs, in that CHCs have more experience working together, and in the main, a more sincere belief in the benefits of a multidisciplinary team. Furthermore, historical challenges of a medical hierarchy as it relates to true team working are eased in a CHC setting.

The Reimbursement section illustrated the strengths and weaknesses of salary and capitation payment mechanisms, as well as highlighting the consequences of financial incentives on how health care is delivered. Criticisms for both payment schemes, and the fact that $\mathrm{CHCs}$ are now also being forced into receiving financial incentives, make conclusions ill-advised at this time. While the CHC group has been philosophically opposed to financial incentives, it is hard to determine what impact this change will have.

In Access and Continuity, a description of the tradeoffs of competing values and objectives and how each model decides what is an appropriate tradeoff was presented. On one hand, the FHT is more accessible (in terms of sheer numbers) and also provides good continuity of care (in the case of those groups who have converted from another 
model but have not made changes to the way they work). For many people, this is significant. Accessibility in the CHC model is limited based on geographic restrictions and the lower volume of .clients. These are examples of equity dilemmas, and depending on the perspective used, either model may stand out. In this thesis, when access is assessed by paying close attention to what specific services clients have access to, the CHC model proved superior.

Systems of ensuring continuity may not be as sophisticated within a CHC, which could pose a significant risk for their clients. Most $\mathrm{CHCs}$ have grown from small organizations where ensuring continuity was easier, and updating systems to reflect the larger organization is challenging. This is transposed next to a FHT model, where continuity is most likely superior because it is a more traditional component of medical evaluation.

The above components of the framework are often dictated by the final component Governance. Governance is critical to this study as it influences how the elements are contextualized and implemented. Due to the importance of community and nonphysician involvement in decision making, I argue the CHC model stands ahead. Without changing the people who make decisions, the opportunities to move beyond status quo traditional medical model based care are limited.

Based on the above analysis, this thesis contends that the CHC model is better equipped to meet the needs of those people with chronic health conditions. Attention should be paid, however, to the growth and development of certain groups within the FHT model, as there have been some progressive steps. For example, hiring true health promoters is a considerable step away from a traditional medical model paradigm, and 
one that moves towards true PHC. Yet at this time, this is a rare example within the model. Advancement as a FHT sector will require an open mind and willingness to learn and change from traditional ways of working. 


\section{Conclusion}

This thesis has demonstrated the need for progressive change in Ontario's primary health care system, specifically looking at how two models of PHC are organized to care for chronic conditions. The intention was to highlight the needed shift from a medical model ideology to a broader definition of health that in turn, offers clients a multidisciplinary team, self management skills, egalitarian relationships, and system navigation. If policy makers and health care providers are not responsive to this challenge, Ontarians will continue to receive sub-par care for their chronic health conditions.

Change in this direction requires acceptance that people's experience of health is personal and multidimensional, and that care must be aligned appropriately. In chronicity, health promotion and population health perspectives are often of equal or greater importance than standard medical treatment. This thesis is timely because the burden of chronicity is growing, new systems of caring for chronicity are being developed, and PHC reform is hitting its stride. Models of PHC must be responsive to the needs of people living with a chronic condition. These needs have evolved and traditional primary care is not always able to meet these needs.

A review of the competing values of stakeholders has shown that despite apparent support for a PHC system that is more responsive to the broader health needs of those with chronicity, historical barriers to change have stifled the implementation of such policy. This is seen specifically in the difficulty of translating the values expressed in Canadian policy documents into primary health care reality. The medical model, often used by the medical profession to perpetuate an ongoing level of medical dominance, has 
been a large part of the resistance. This power imbalance among the key stakeholders has resulted in the values and needs of those with chronicity being trumped by powerful groups such as physician associations and the state.

Determining which PHC model is better equipped to deal with chronicity can be evaluated on two levels. The first assesses the guiding philosophy of each model, considering how it embodies and balances the values presented in Chapter Two. The second is a practical consideration of the elements as presented in Chapter Four.

In the first level, it is safe to say that many Ontarians would align themselves philosophically with a CHC model that espouses concepts of health promotion, community engagement and egalitarianism, over the FHT that is guided by a more traditional approach to health care. Simply put, Ontarians connect more with a valuedriven organization over one that is profit-driven. Yet this does not suggest that Ontarians do not relate to the reluctance of providers to make a substantial commitment to health promotion activities. This reluctance from providers stems in part from longheld doubts about the benefits of health promotion activities and, in part, from a fear that a greater emphasis may lead to uncontrollable demands for such services (Wilner, 1986).

I argue that the hegemony of the medical model is responsible for these doubts of health promotion activities, and only by breaking down the historical and attitudinal barriers can we hope for true progressive change. Realizing true change and moving beyond medical model ideology requires different people at the decision making table. Comparing the governance structure of each model highlighted that in the majority of FHT cases, this is not possible due to the dual role of physicians as health care providers 
and directors of the board. In order to change the way care is delivered, we must allow new players (e.g., non-physicians) to make decisions.

This first level of evaluation is meaningful, because values can dictate how practical services are delivered. They can allow teams to break away from outdated ideology, better meet client needs by embracing health promotion practices and addressing the root causes of illness. On the other hand, they can also keep teams from truly working together and continue services in a medical model, financially motivated environment. With this in mind, the $\mathrm{CHC}$ model stands out because its core values (such as commitment to community health, health promotion concepts, and multidisciplinary teams) are more closely aligned with primary health care characteristics and the needs of the people who use the system, rather than aligned with the needs of other stakeholders.

The second level of this evaluation, while theoretical, is more pragmatic. After reviewing the importance of values in the above section, one must consider the costs associated with a value-driven organization. A good example to consider is Access. By all accounts, CHC providers care for fewer people than providers in a FHT model (Ontario Health Quality Council, 2008). Legitimate arguments are made that CHCs are home to more complicated clients who require more time; this notion clearly applies to chronicity as well. Yet reconciling the fact that $\mathrm{CHC}$ clientele receive 'Cadillac care', while other Ontarians have no access to PHC is troubling.

The answer, in my view, is again found in the quest for progressive change. Rather than succumbing to status quo medical model ideology and defending it with the claim that more people have access to care, the provincial goal should be to provide superior, 
value-based, PHC to everyone. This is a system-level problem that requires resources to be redistributed toward models that embody PHC.

Based on the historical attitudes of the people involved, I propose that at the present time, FHTs are less equipped to deal with the full range of needs of those with chronicity. I argue that most physicians are enrolling in FHTs not because they feel it provides enhanced care for clients, but more because it is being mandated by the government. Many providers feel changes to $\mathrm{PHC}$ are based on cost reduction (a multidisciplinary team being less expensive than traditional individual physicians) and on offering an improved quality of life for physicians, through improved on-call arrangements, after hours tele-health, and additional support. Meanwhile, the literature and non-physician providers believe that a team-based approach offers improved care over traditional primary care. This does not suggest that FHT providers do not favour health promotion activities; the issue is that they define it in different terms relative to $\mathrm{CHC}$ providers, and the result is that non-medical determinants of health that are critical to chronicity, such as poverty, food security and literacy, will be inadequately managed. This is a major problem in the context of chronic disease prevention and management.

This thesis has demonstrated that there is a system disconnect, where the quest for true PHC battles the 'tyranny of the acute.' This battle is exemplified in the comparison of the CHC and FHT models. The issues presented, while focused on primary health care, transcend any single level and can be applied to entire health care system. Despite obstacles and barriers that remain, considerable changes are occurring that should offer much hope for those who care about the future of health care in Ontario. 


\section{Future Considerations}

This analysis leads to several questions for future consideration. First, the decisions made to align or harmonize existing primary health care delivery models may result in the homogenization of the two models, where the priorities of the stronger group will prevail. This may also lead to competition between the two models, which can be seen already, and which could force CHCs to forgo certain values. If so, there is a fear that these cost-control measures similar to U.S. based HMOs may be implemented. Second, financial incentives are justified as rewarding physicians who practice in a cost-conscious manner. If it is a cost reducing objective, the next logical step may be a monitoring of costs, and provider decisions about care provision, will be included as one of the metrics which is also very reminiscent of the HMOs. This is critical in the context of chronicity, because the choices available for these clients are often costly. Third, an important sidebar to this discussion is the parallel reform in Ontario's healthcare. Regionalization has introduced a new jurisdictional player to the health policy arena as governments devolved responsibilities for the funding, management, and delivery of health services to these new governing structures. As seen in other provinces, funding for physician services (and hence the bulk of primary healthcare) has been excluded from the regional health authority budgets, once again leaving policymakers with little weight over primary health care organization and delivery.

One of the most important pieces of future research in this area pertains, ironically, to measurement. Community Health Centres must forge a new path, and become equipped to share their successes and offer knowledge exchange to FHTs and others in the system. In order to make a true difference, and perhaps change the attitude of those with a 
traditional mindset, the Community Health Centre model must provide more evidence that long-term investment in health promotive activities within primary health care offer improved outcomes. More examples like the recent 2008 Ontario Quality Health Council report (which positioned CHCs ahead of other models due to their effort in social determinants of health) are required in order to garner wide support among all stakeholders.

Therefore, much like the challenges CHCs have faced along the path of true PHC, the next challenge is an evolution - to empirically capture how their 'subjective' work which is meaningful and enriching to their clients (and so critical to chronicity) is making a difference to their health status. This is the work PHC should tackle, because it is this work that truly determines one's health status. 


\section{Glossary}

AFHT - Association of Family Health Teams

CDPM - Chronic Disease Prevention and Management

CHC - Community Health Centre

EHR - Electronic Health Record

EICP - Enhancing Interdisciplinary Collaboration in Primary Health Care

FHT - Family Health Team

MOHLTC - Ministry of Health and Long Term Care

PHC - Primary Health Care

HMO - Health Maintenance Organization

HP - Health Promotion

HSO - Health Service Organization

NP - Nurse Practitioner

OMA - Ontario Medical Association 
Appendix A: Acute versus Chronic

\begin{tabular}{|c|c|c|}
\hline & Acute disease & Chronic Illness \\
\hline Onset & Abrupt & Generally gradual and often insidious \\
\hline Duration & Limited & Lengthy and indefinite \\
\hline Cause & Usually single & $\begin{array}{l}\text { Usually multiple and changes over } \\
\text { time }\end{array}$ \\
\hline $\begin{array}{l}\text { Diagnosis and } \\
\text { prognosis }\end{array}$ & Usually accurate & Often uncertain \\
\hline Intervention & Usually effective & $\begin{array}{l}\text { Often indecisive; adverse effects } \\
\text { common }\end{array}$ \\
\hline Outcome & Cure possible & No cure \\
\hline Uncertainty & Minimal & Pervasive \\
\hline Knowledge & $\begin{array}{l}\text { Health Care Provider is } \\
\text { knowledgeable. Patient is } \\
\text { inexperienced }\end{array}$ & $\begin{array}{l}\text { Health Care Provider and patients have } \\
\text { complementary knowledge and } \\
\text { experience }\end{array}$ \\
\hline
\end{tabular}

(Holman \& Lorig, 2000) 


\section{Appendix B: OMA Feature - OMA Policy Paper: Comprehensive Primary Care}

\section{Summary of Recommendations:}

\section{Defining Primary Medical Care}

Primary medical care draws on the unique skill-set of the comprehensive primary care physician, coupling the diagnosis, treatment and management of health problems with the provision of illness prevention and health promotion services. At the core of primary medical care is the patient-physician relationship, which includes the essential elements of:

1. First Contact Care

2. Family Centred Care

3. Co-ordination of Care

4. Longitudinal Care

5. Comprehensive Care

Primary health care incorporates primary medical care, but places a greater emphasis on the broader determinants of health, including population health, sickness prevention and health promotion, with services provided by comprehensive primary care physicians and other providers, often in group practice and multi-disciplinary teams.

\section{Defining Comprehensive Care}

The Ontario Medical Association (OMA) supports the definition of comprehensive care outlined in recent Agreements with government (Appendix A). We support and value the various ways in which primary comprehensive care physicians deliver quality care to their patients.

\section{The Patient-Physician Relationship}

The patient-physician relationship must remain central within every primary care model and the role of the physician as the coordinator of care must be supported and promoted within the health-care system.

Every patient in Ontario should have the opportunity to enter into a relationship with a physician who commits to the ongoing provision of primary care to that person.

\section{Interprofessional Care and Funding}

The OMA believes that in an effort to provide every patient in Ontario with access to a comprehensive primary care physician, opportunities for collaboration between physicians and allied health professionals should be expanded. Programs should be introduced that compensate physicians for providing clinical leadership and that allow all physicians, regardless of remuneration model, to work with other allied health professionals. 
Funding should be extended to all physicians to work with allied health professionals and fees should be made available for physician time spent in consultation and collaboration with such providers.

\section{Interprofessional Care and the Role of the Comprehensive Care Physician}

Within collaborative teams in primary care, the comprehensive primary care physician should be acknowledged as the clinical lead.

Physicians should be involved and represented in the development of all future interprofessional care models in Ontario.

\section{Interprofessional Care and Referrals to Specialists}

The comprehensive primary care physician should be the only member of the primary health care team responsible for determining when the skill-set of the team has been exceeded and when a referral is necessary.

\section{Interprofessional Care and Linking Primary and Specialized Care}

Opportunities for shared care should be expanded, as should programs and funding that promote a greater degree of interaction/collaboration between comprehensive primary care physicians and their specialist colleagues.

\section{Interprofessional Care and Liability}

Before joining a team-based practice, every physician should seek assurances that the other team members have adequate liability protection. The physician leaders of teambased practices should require evidence of liability protection as a condition of employment for all non-physician allied health professionals.

\section{Rostering and Patient Accountability}

The physician or group of physicians should be the only healthcare providers to whom patients roster.

Patient accountability should be enshrined in all primary care models and patients should be actively encouraged to contact their comprehensive primary care physician, or his or her group, before seeking medical advice or treatment elsewhere.

\section{Negation}

Comprehensive primary care physicians should not be financially penalized when their patient requires specialized care offered by a non-specialist physician in focused practice.

\section{Information Technology and System Integration}

The MOHTLC should fund a system-wide electronic clinical management system that supports information management and knowledge transfer at the point of care. There should be guaranteed, long-term funding that will cover future operational costs and that will allow for system-wide integration. All physicians should be eligible for this funding.

\section{Remuneration and Equity}


All physicians practising comprehensive care should have the right to practise in any model he or she chooses and financial and non-financial incentives should be equally offered to all of these physicians. We recognize that in some circumstances, non-family physicians may practise comprehensive primary medical care; these doctors should be eligible for the same incentives as family physicians practising comprehensive care.

\section{Blended Remuneration Models}

The OMA recognizes that no payment model is ideal and that in any new model efforts should be made to promote the benefits and attenuate the disadvantages of each.

\section{Chronic Disease Management and Out of Office Care}

Physicians should be adequately compensated for office procedures and support given for out-of-office care provided to their patients (i.e. emergency care, hospital care, obstetrics, home care and long-term care). The OMA supports the development of models and incentives that promote preventive medicine, early detection of illness and chronic disease management. (OMA Policy Paper) 
Appendix C - Indicators used in 2003 Health Care Accord (http://www.hcsc.gc.ca/hcs-sss/delivery-prestation/fptcollab/2003accord/index-eng.php)

\title{
Timely Access Indicators
}

\section{Access to health care providers/services}

\author{
$\%$ of population having a regular family doctor (FMM 2000) \\ $\%$ of doctors accepting new patients \\ number of multi-disciplinary primary health care \\ organizations or teams by region (rural/urban) \\ $\%$ of population having access to $24 / 7$ primary care provider \\ (e.g, nurse practitioner, doctor)/telehealth/online health \\ information \\ $\%$ of population routinely receiving needed care from a \\ multi-disciplinary primary health care organization or team \\ $\%$ of population with public coverage of core set of home \\ care services
}

Wait Times/Volume measures for

radiation therapy for breast and prostate cancer, cardiac bypass surgery, hip and knee replacement surgery (FMM 2000)

referral to specialists for cancers (lung, prostate, breast, colo-rectal), heart and stroke emergency rooms from entry to discharge (seasonally adjusted)

diagnostic tests (MRI, CT)

from referral to provision of first home care service waiting period before being eligible for public coverage of home care services in another jurisdiction proportion of services/facilities linked to a centralized (provincial/regional) wait list management system for selected cancers and surgeries, referral to specialists, emergency rooms and diagnostic tests (all of the above wait time indicators)

Catastrophic Drug Coverage

to be developed

\section{Quality Indicators}

\section{Patient Safety}

reported medical error/events (e.g., disease surveillance, adverse drug reactions) - to be determined by proposed Institute on Patient Safety 
Patient Satisfaction (FMM 2000)

overall health care services

hospital care

physician care

community-based health care

telehealth/online information

Health Outcomes

readmissions for selected conditions

AMI, pneumonia (FMM 2000)

congestive heart failure, GI haemorrhage

mortality rate for cancers (FMM 2000)

survival rate for cancers (FMM 2000)

\section{Sustainability (Efficiency and effectiveness) Indicators}

Health Human Resources

age distribution of practicing providers by area of specialty number of providers (by specialty) leaving/entering the system each year a 10-year rolling forecast of providers expected to enter system (trained in Canada, incoming from other countries)

\section{Equipment}

number and types of equipment installed number of diagnostic professionals to operate equipment volume flow/wait times for MRI, CT (covered under access indicators)

\section{Information Systems}

progress on building information systems degree of standardization of information collected and shared for evidence-based decision-making degree of technology utilization based on evidence

\section{Value for Money - qualitative indicators primarily}

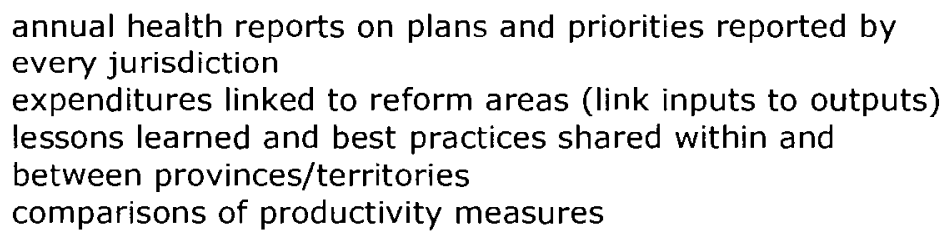

Health Status and Wellness 
$\%$ of Canadians engaged in physical activities

$\%$ of Canadians with recommended Body Mass Index (BMI)

Potential years of life lost (PYLL)

Disability-Free Life Expectancy (DFLE)

Cost of Illness 


\section{Appendix D: Ontario's CDPM Framework}

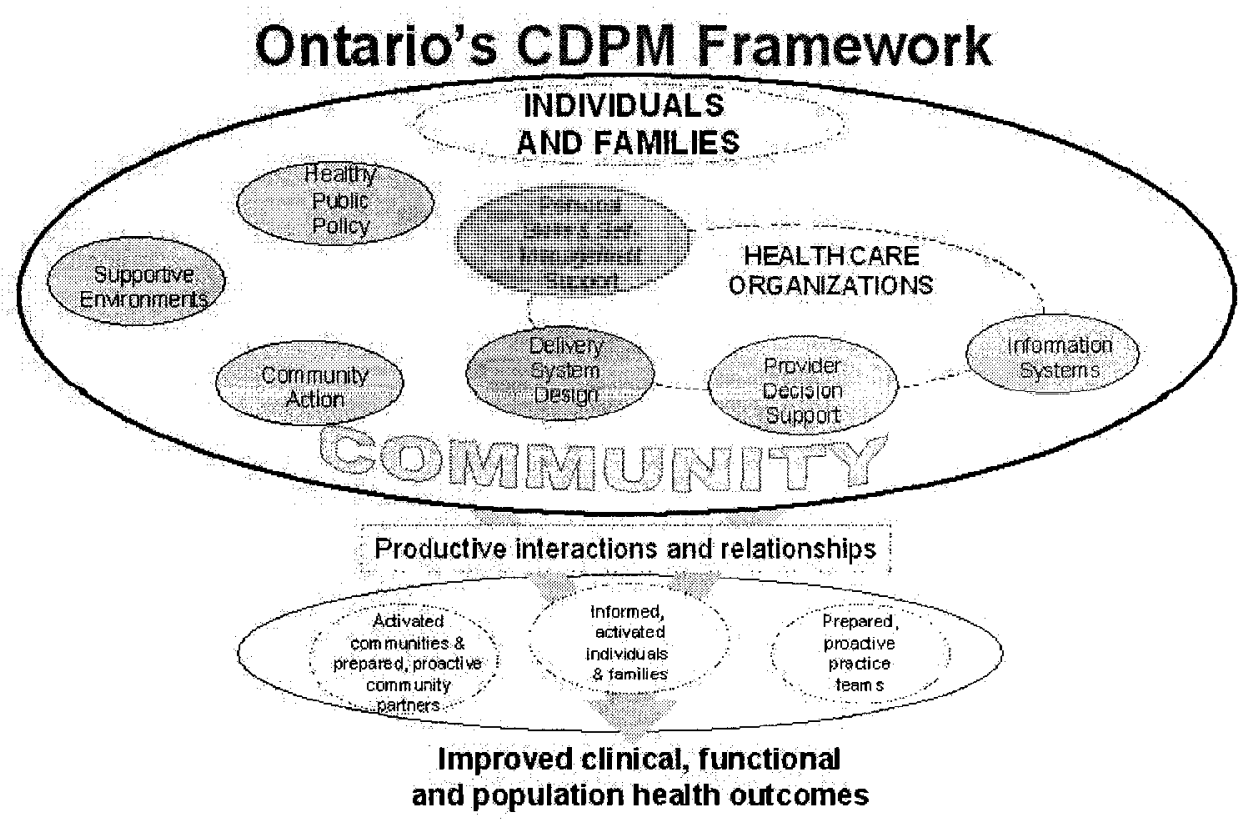

MOHLTC Chronic Disease Prevention and Management Framework. January 2006

\section{CDPM model (Presentation, MOHLTC)}

Health Care Organizations - make systematic efforts to improve prevention and management of chronic disease:

- strong leadership (e.g., CDPM champions)

- alignment of resources, incentives (e.g., OMA agreement, Admin support, IT support for providers, etc.)

- accountability for results (e.g., set goals, measure effectiveness in improving outcomes for clients, population and system )

Delivery System Design - focus on prevention and, improve access, continuity of care and flow through the system:

- interdisciplinary teams (e.g., defined roles \& responsibilities)

- integrated health promotion and disease prevention (e.g., nutrition and physical activity counselling)

- planned interactions, active follow-up (e.g., care paths, case management)

- adjustments, innovations in practice (e.g., group office visits, central appointment booking service)

- outreach and population needs-based care (e.g., Latin American Diabetes)

Provider Decision Support - integrate evidence-based guidelines into daily practice:

- easily accessible clinical practice guidelines (e.g. web-based, interactive) 
- tools (e.g. disease/risk assessment, management flow sheets, drug interaction software)

- provider alerts and reminders (e.g. reminders for tests, examinations)

- access to specialist expertise (e.g. team social worker; cardiologist at tertiary care centre)

- provider education (e.g. working in interdisciplinary teams, collaboratives)

- measurement, routine reporting/feedback, evaluation (e.g. continuous quality improvement loop for target blood glucose levels in client population with diabetes)

Information Systems - are essential for enhancing information for providers to provide quality care; for clients to support them in managing their disease on a day to day basis; and for integrating services across health system:

- electronic health records (e.g. personal health information, test results, prevention and treatment plans)

- client registries to identify and provide patient subpopulations with proactive care, monitoring, and follow-up (e.g. tracking systems, automated reminders)

- links (e.g. between team members, care centres)

- information for clients (e.g. health care advice, access to records, community resources)

Personal Skills \& Self-Management Support - organizations empower individuals to build skills for healthy living and coping with disease:

- emphasizing the individual's and families' central role in their health, and as a member of the care team

- engaging them in shared decision-making, goal-setting and care planning

- providing access to education programs \& health information (e.g. asthma education programs, consumer information)

- behaviour modification programs (e.g. smoking cessation)

- counselling and support services (e.g. self-management support groups)

- integration of community resources (e.g. referral to community physical activity programs)

- follow-up (e.g. reminders, self-monitoring assistance)

Healthy Public Policy - develop and implement policies to improve individual and population health and address inequities:

- legislation, regulations (e.g. smoking by-laws)

- fiscal, taxation measures (e.g. lowering duty on imported fruit)

- guidelines (e.g. Health Canada food guidelines, screening)

- organizational change (e.g. flex hours, day care in the workplace)

Supportive Environments - remove barriers to healthy living and promote safe, enjoyable living and working conditions:

- physical environments (e.g. safe air, clean water, accessible transportation, affordable housing, walking trails, bicycle lanes) 
- social and community environments (e.g. daily physical activity in schools, seniors programs in community centres, on-site health promotion programs in the workplace)

Community Action - encourage communities to increase control over issues affecting health:

- collaboration between the health care sector and community organizations (e.g. Latin American Diabetes Program, London ON)

- effective public participation and intersectoral collaboration (e.g. community members, private sector and schools providing breakfast nutrition/physical activity programs)

- The organization links to community agencies that assist patients with chronic illness and has referral systems to such agencies. 


\section{Appendix E: B. Starfield's Framework (Starfield, 1998)}

Personnel: This includes all who are involved in providing the services and their education and their training.

Facilities and equipment: These include the buildings and the physical components of the facilities including such elements as laboratory instruments and technology for diagnosis or therapy.

Management and amenities: These include characteristics of services other than those directly related to clinical care. For example, are laboratory results reported in a timely fashion? Are patients treated with courtesy and respect?

Range of Services provided by facilities: This range of services may vary from country to country and from community to community, but every facility has made decisions about the kinds of services that will be available and those that will not be available. The range of services provided is an important consideration for the nature of primary care.

Organization of services: Do the personnel work alone or in groups? What are the mechanisms for ensuring accountability, and who is responsible for providing the different aspects of care?

Mechanisms for providing continuity of care: These mechanisms are especially important in primary care because without them there would be no way to deal with problems that require more than one visit or require the transfer or information. Continuity is usually provided in the form of practitioners or team of practitioners who serve as the primary contact for the patient, but sometimes the only mechanism for continuity is some form of medical record.

Mechanisms for providing access to care: There is no point in having personnel, facilities and equipment if they cannot be reached by persons who need them. There are several types of accessibility: Accessibility in time, i.e., the hours of availability, wait times for an appointment, in-office wait, ability to see a provider without an appointment; geography, i.e., is transportation adequate to meet distance covered, is the space near to the population it serves; declining number of family physicians; and psychosocial accessibility.

Arrangements for financing: What is the method of payment for services, and how are the personnel remunerated for their work? Of all the structural features, this one is most likely to differ across the countries and therefore a feature of great interest crossnationally for comparative studies.

Delineation of the population eligible to receive services: Each unit of the health services system should be able to define the community it serves and should know its important sociodemographic and health characteristics. Members of the population should be able to identify their source of care and be aware of its responsibility for 
providing required services. This structural feature is another critical element for primary care, especially for the feature known as longtitudinality.

Governance of the health care system: health systems differ in their accountability to those they serve. Often they do not involve the population at all in decisions about the way services are organized or delivered. Sometimes, community councils serve in an advisory capacity. Rarely is responsibility for decision making shared or assumed by community boards. 


\section{Appendix F: Comparison of Board members}

\section{Sandyhill CHC - Board of Directors}

Delivering better care and healthier communities

2007-2008 Board of Directors

(http://www.sandyhillchc.on.ca/mainEngl/board.html)

- May Morpaw - President

- Jean-Jacques Desgranges - Vice-President for Internal Issues

- Didier Delahousse - Treasurer

- Kent Woodhall - Secretary

- David Gibson - SHCHC's Executive Director (Ex-officio)

- Josée Anne Gauthier - Staff Representative

- Stephen McFadden - Staff Representative

- Siobhan Harty - Board Director

- Mana Herel - Board Director

- Christine Honsl - Board Director

- Lynsey James - Board Director

- William Kelly - Board Director

- Bob Mather - Board Director

- Lynne Moffatt - Board Director

- Camille Papanek - Board Director

- Stephen Samis - Board Director

- Swapna Stephen - Board Director 
Hamilton Family Health Team - Board of Directors

(http://www.hamiltonfht.ca/about-us/board-of-directors)

\begin{tabular}{ccc} 
Date & \multicolumn{2}{c}{ Renewed Year } \\
Elected & Term & Term Term Ends
\end{tabular}

\section{Current Board Members}

\begin{tabular}{|c|c|c|c|c|c|}
\hline Dr. Kenneth & Burgess & 13-Feb-06 & $3 \mathrm{yrs}$ & & 2009 \\
\hline Dr. Brenda & Copps & 13-Feb-06 & 3 yrs & & 2009 \\
\hline Dr. John (Giovanni) & Corsini & 16-May-06 & $2 \mathrm{yrs}$ & & 2008 \\
\hline Dr. Mehboob & Damji & 7-May-07 & 3 yrs & $3 \mathrm{yrs}$ & 2010 \\
\hline Dr. Bruno Leo & Di Paolo & 16-May-06 & $1 \mathrm{yr}$ & 3 yrs & 2010 \\
\hline Dr. Allen & Greenspoon & 13-Feb-06 & $2 \mathrm{yrs}$ & & 2008 \\
\hline Dr. Martin R. & Jackson & 16-May-06 & 3 yrs & & 2009 \\
\hline Dr. Cornelia & Mielke & 16-May-06 & $1 \mathrm{yr}$ & $3 \mathrm{yrs}$ & 2010 \\
\hline Dr. Jean & Mullens & 16-May-06 & $1 \mathrm{yr}$ & $3 \mathrm{yrs}$ & 2010 \\
\hline Dr. Adrian & Hornich & 15-Jan-08 & 3 yrs & 3 yrs & 2010 \\
\hline Dr. Domenic & Rosati & 16-May-06 & $3 \mathrm{yrs}$ & & 2009 \\
\hline Dr. Richard Henry & Tytus & 16-May-06 & $2 \mathrm{yrs}$ & & 2008 \\
\hline
\end{tabular}

Previous Board Members

$\begin{array}{lllll}\text { Dr. Lionel } & \text { Sewchand } & \text { 16-May-06 } & 1 \text { yr } & 2007 \\ \text { Dr. Tony } & \text { Opie } & 16-\text { May-06 } & 2 \text { yrs } & 2008\end{array}$




\section{Appendix G: AFHTs Website, Information for Providers}

(http://www.afhto.com/for-providers)

\section{For Healthcare Providers}

Information and resources for healthcare providers

Information and resources for:

- Doctors

- July 2007 - Colorectal Cancer Screening Program (5 page Word 61kb)

- Collaborative Care - A medical liability perspective (16 page PDF)

- Access to healthcare

- Primary healthcare metrics (2 page PowerPoint, 41KB)

- Salary model for doctors

- January 2007 - Income Stabilization for Blended Salary model fact sheet (PDF)

- December 2006 - Blended Salary model fact sheet for physicians (PDF)

- Blended Salary model letter for physicians (PDF)

- Income stabilization fact sheet for physicians (PDF)

- Nurses

- Primary care payments: CCM, FHG, FHN, FHT, FHO(PowerPoint)

- Organizational adjustments to support a collaborative initiative

- Collaborative Practice: Are Nurses Employees or Self-Employed? A brief note from the Canadian Nurses Protective Society (PDF)

- Professional Liability Protection for Nurses by Nurses - A letter to Dr.

Wendy Graham from the Canadian Nurses Protective Society (PDF)

- Improving Office Practice: Work smarter, not harder

- Dietitians

- Pharmacists

- Ontario Pharmacists' Association's Resource Kit for FHTs (32 page PDF)

- Ontario Pharmacists' Association

- Social Workers

- Mental Health Workers

- Occupational Therapists

- Health Educators 


\section{Bibliography}

Abelson, J., \& Eyles, J. (2002). Public Participation and Citizen Governance in the Canadian Health System. Commission on the future of health care in Canada, discussion paper no. 7, 1-37.

American Nurses Association (2003). American nurses association testimony before the federal trade commission and department of justice on perspectives of competition policy and the health care marketplace. Retrieved October 5, 2006, from http://www.ftc.gov/ogc/healthcarehearings/docs/030227carsonwinifredy.pdf

Armstrong, P., Armstrong, H., \& Coburn, D. (Eds.). (2001). Unhealthy Times: Political Economy Perspectives on Health and Care in Canada. Don Mills: Oxford University Press.

Bachrach L. (1993). Continuity of care and approaches to case management for long-term mentally ill patients. Hospital and Community Psychiatry, 44, 465-8.

Bailey, P., Jones, L., \& Way, D. (2006). Family physician/nurse practitioner: stories of collaboration. Journal of Advanced Nursing, 53 (4), 381-391.

Bloom, J., Hu, T., Wallace, N., Cuffel, B., Hausman, J., Sheu, M., \& Scheffler, R. (2002). Mental health costs and access under alternative capitation systems in Colorado. Health Services Research, 37 (2), 315-340.

Bodenheimer T. \& Grumbach K. (1996). Capitation or decapitation. Keeping your head in changing times. Journal of the American Medical Association, 276:1025-31.

Bodenheimer, T., Lorig, K., Holman, H., \& Grumbach, K. (2002a). Patient selfmanagement of chronic disease in primary care. Journal of the American Medical Association, 288, 2469-2475.

Bodenheimer, T., Wagner, E., \& Grumbach, K. (2002b). lmproving primary care for patients With Chronic 1llness. Journal of the American Medical Association, 288(14), 1775-1780.

Bolen, C. (2000). Towards unity for health. Challenges and opportunities for partnership in health development (Document WHO/EIP/OSD/2000.9). Geneva: World Health Organization.

Booth, JD., Sapp, S., \& Ferguson, J. (1996). Payment by capitation and the quality of care. The New England Journal of Medicine, 335, 1227-1231.

Bourdieu, P. (1989). Social space and symbolic power. Sociological Theory, 7 (1), 14 25. 
Broemeling A-M., Watson D.E., \& Prebtani F. (2008). Population patterns of chronic health conditions, co-morbidity \& healthcare use in Canada: Implications for policy \& practice. Healthcare Quarterly, 11 (30), 70-76.

Bunton, R., \& Macdonald, G. (Eds.). (1991). Health Promotion: Disciplines, diversity and developments. London and New York: Routledge.

Canada Health Act of 1984, c.6, s.1. (1984). Retrieved July 30, 2008, from: http://laws.justice.gc.ca/en/ShowFullDoc/cs/C-6///en

Canadian Alliance of Community Health Centres (2007). Building Better Teams: A Toolkit for Strengthening Teamwork in Community Health Centres. Toronto.

Canadian Health Services Research Foundation. (2001). Open grants competition: call for letters of intent. Retrieved September 23, 2003, from www.chsrf.ca/programs/archives/ogc/2001-call e.shtml

Canadian lnstitute for Health Information (2003). National Health Expenditure Trends: 1975-2003. Ottawa: Author.

Canadian Institute for Health Information (2006). Understanding Physician Satisfaction at Work: Results from the 2004 National Physician Survey. Retrieved January 11, 2007, from http://secure.cihi.ca/cihiweb/en/downloads/hhr_physicians analysis in brief nov2006 e . .pdf

Charmaz, K. (2000). Experiencing Chronic Illness. In G.A. Albrecht, R. Fitzpatrick \& S. Scrimshaw (Eds.), The Handbook of Social Studies in Health and Medicine (p. 277 290). London: Sage Publications.

Clark. N.M (2003). Management of chronic disease by patients. Annual Review of Public Health, 24, 289-313.

Clement, W., \& Williams, G. (Eds.). (1989). The new political economy. McGillQueen's Press: Montreal.

Coalition of Community Health and Resource Centres of Ottawa. (2005). Our community health centres: Essential today. The model for tomorrow. Retrieved May 6, 2007, from http://www.coalitionottawa.ca/html/benefits.html

Coburn, D., Rappolt, S., \& Bourgeault, I. (1997). Decline vs. retention of medical power through restratification: an examination of the Ontario case. Sociology of Health and Illness, 19(1), 1-22.

Coburn, D. (2004). Beyond the income inequality hypothesis: class, neo-liberalism, and health inequalities. Social Science \& Medicine, 58, 41-56. 
Coburn D., \& Willis E. (1998). The medical profession: knowledge, power and autonomy. SAGE International Handbook of Medical Sociology.

Coburn, D. (2006). Medical Dominance Then and Now: Critical Reflections. The International Journal of Health Sociology: Policy, Promotion, Equity \& Practice, 15(5), 18-30.

Coburn, D., D'Arcy, C., \& Torrance, M. (1998). Health and Canadian society: Sociological perspectives. Toronto: University of Toronto Press.

College of Nurses of Ontario (2007). Entry-to-practice competencies for Ontario registered nurses. Toronto: College of Nurses of Ontario.

College of Family Physicians of Canada. (2001). Initial data release of the 2001 national family physician workforce survey. Toronto.

Condrad, P. (2005). The sociology of health and illness: Critical perspectives, 7 th edition. New York: Worth Publishers.

Cote, P., \& Wickremaarachi, S. (2004). Blueprint for comprehensive primary health care reform in Ontario. Toronto: Author.

Deber R, Narine L, Baranek P, Sharpe N, Duvalko KM, Zlotnik-shaul R, Coyte P, Pink G, \& Williams P. (1998). The public-private mix in health care. National Forum on Health (Canada).

Denis, JL. (2002). Governance and Management of Change in Canada's Health System. Commission on the future of health care in Canada, discussion paper No. 36, 1-36.

Devlin, R., Sarma, S. \& Hogg, W. (2006). Remunerating primary care physicians: Emerging directions and policy options for Canada. Law and Governance, 10 (6), 16-33.

Dubois, C. (2004). Implementing primary healthcare reform: Strategies to align stakeholder support. Montreal: Canadian Health Services Research Foundation. Retrieved on May 17, 2007, from http://www.chsrf.ca/research themes/pdf/PCseminar_e.pdf

Evans, R. (1983). Health care in Canada: Patterns of funding and regulation. Journal of Health Politics, Policy and Law. 8(1), 1-43.

Evans, R. (1993). Health care reform: 'The issue from hell.' Policy Options, 35-41.

Federal, Provincial and Territorial Advisory Committee on Population Health. (1994). Strategies for population health: Investing in the health of Canadians. 
Flood, C., Tuohy, C., Stabile, M. (2004). What is in and out of medicare? Who decides? (CHSRF-MOHLTC Research Project "Defining the Medicare Basket" RC2-0861-06). Toronto, ON: Institute of Research and Public Policy.

Fooks C. (2004). Implementing Primary Care Reform in Canada: Barriers and Facilitators. School of Policy Studies Queen's University Kingston, Ontario: McGillQueen's University Press.

Frankish, J., Moulton, G., Rootman, I., Cole, C \& Gray, D. (2006). Setting a foundation: underlying values and structures of health promotion in primary health care settings. Primary Health Care Research \& Development, 7, 172-182.

Friedson, E. (1988). Profession of medicine. London: University of Chicago Press Ltd. Fuller, Colleen. (1998). Caring for profit: How corporations are taking over Canada's health care system, Vancouver: New Star Books.

Giacomini, M., Hurley, J., Gold, I., Smith, P., \& Abelson, J. (2004). The policy analysis of 'values talk': lessons from Canadian health reform. Health Policy, 67, 15-24.

Gillett, J., Hutchison, B., Birch, S. (2001). Capitation and primary care in Canada: financial incentives and the evolution of health services organizations. International Journal of Health Services, 31 (3), 583-603.

Glazier, R. (2007). Balancing equity issues in health systems: Perspectives of primary healthcare. Healthcare Papers, 35-46.

Gofin, Jaime \& Gofin, Rosa (2005). Community-oriented primary care and primary health Care. American Journal of Public Health, 95 (5), 757.

Government of British Columbia. (1991). British Columbia Royal Commission on Health Care and Costs. Victoria: Author.

Grignon, M., Paris, V., \& Polton, D. (2002). Influence of physician payment method on the efficiency of the health care system (Discussion paper no. 35, Catalogue No. CP3279/35-2002E-IN). Ottawa: Commission on the Future of Health Care in Canada.

Haggerty, J., Reid, R., Freeman, G., Starfield, B., Adair, C., \& McKendry, R. (2003). Continuity of care: a multidisciplinary review. British Medical Journal, 327, 1219-1221.

Hall, M., Dugan, E., Balkishnan, R., \& Bradley, D. (2002). How disclosing HMO physician incentives affects trust. Health Affairs, 21(2), 197-206. 
Haydon, E., Roerecke, M., Giesbrecht, N., Rehn, J., \& Kobus-Matthews M. (2006). Chronic disease in Ontario and Canada: Determinants, risk factors and prevention priorities. Toronto, ON: Ontario Chronic Disease Prevention Alliance \& the Ontario Public Health Association.

Hayward, K., \& Colman, R. (2003). The tides of change: addressing inequity and chronic disease $n$ Atlantic Canada. Halifax: Population and Public Health Branch, Atlantic Regional Office.

Health Canada. (2002). The economic burden of illness in Canada, 1998. Ottawa: Author.

Health Canada. (2007). Objectives of the primary health care transition fund. Retrieved August 4, 2007, from:

http://www.hc-sc.gc.ca/hes-sss/prim/phetf-fassp/object-eng.php

Health Canada. (2008). About primary health care. Retrieved January 10, 2008, from: http://www.hc-sc.gc.ca/hcs-sss/prim/about-apropos-eng.php

Health Council of Canada. (2007). Health care renewal in Canada: Measuring up? Retrieved February 14, 2007, from:

http://www.healthcouncilcanada.ca/docs/rpts/2007/HCC MeasuringUp_2007ENG.pdf

Health Promotion Agency. (2008). 1974 Lalonde Report. Retrieved March 5, 2008, from: http://www.healthpromotionagency.org.uk/Healthpromotion/Health/section6a.htm

Health Services Restructuring Commission (Duncan Sinclair, Chair). (1999). Primary health care strategy - Advice and recommendations to the Honourable Elizabeth Witmer, Minister of Health, Government of Ontario.

Hoffman, K. \& Dupont, JM. (1992). Community Health Centres and Community Development. Ottawa: Health Services and Promotion Branch, Health and Welfare Canada.

Hogg, W., Rowan, M., Russell, G., Geneau, R., \& Muldoon, L. (2007). Framework for primary care organizations: the importance of a structural domain. International Journal for Quality in Health Care, 1-6.

Holman, H., \& Lorig, K. (2000). Patients as partners in managing chronic disease. British Medical Journal, 320, 526-527.

Hroscikoski, M., Solberg, L., Sperl-Hillen, J., Harper, P., McGrail, M., \& Crabtree, B. (July/August 2006). Challenges of change: A qualitative study of chronic care model implementation. Annals of Family Medicine, 4(4), 317-326. 
Hurley J, Hutchison B, Giacomini M, Birch S, Dorland J, \& Reid, R. (1999). Policy considerations in implementing capitation for integrated health systems. Ottawa: Canadian Health Services Research Foundation.

Hutchison, B., Abelson, J., \& Lavis, J. (2001). Primary care in Canada: So much innovation, so little change. Health Affairs, 20(3), 116-131.

Institute of Medicine (2001). Committee on Quality of Health Care in America. Crossing the Quality Chasm: A New Health System for the 21st Century. Washington: National Academy Press.

Jaakkimainen L, Upshur R, Klein-Geltink J., Leong A., Maaten S., Schultz S., \& Wang L. (2006). Primary care in Ontario. Toronto: Institute of Clinical Evaluative Sciences.

Jenson, J. (1994). Commissioning Ideas: Representation and Royal Commissions. In S.D. Phillips (Ed.), How Ottawa spends 1994-1995: Making change, pp. 39-70.

Carleton University Press, Ottawa.

Kassirer JP. (1998). Doctor discontent. New England Journal of Medicine, 339 (21), 1543 .

Kirby, M. (2002). The Health of Canadians - The Federal Role. Reforming Health Protection and Promotion in Canada: Time to Act. Ottawa: Health Canada Standing Senate Committee on Social Affairs, Science and Technology.

Kekki P. (1990). Teamwork in primary health care (ICP/HMD 159/7567r). Copenhagen: World Health Organization, Europublication Series.

Krieger, N. (2001). Theories for social epidemiology in the 21st century: An ecosocial perspective. International Journal of Epidemiology, 30, 668-677.

Labonte, R. (1994). Health promotion and empowerment: reflections on professional practice. Health Education Quarterly, 21(2), 253-268.

Labonte, R (1997). Power, participation and partnerships for health promotion. Victoria: Victorian Health Promotion Foundation.

Lalonde, M. (1974). A New Perspective on the Health of Canadians. Ottawa: Health and Welfare Canada.

Lamarche P., Beaulieu M., Pineault R., Contandriopoulos A., Denis J., \& Haggerty J. (2003). Choices for change: The path for restructuring primary care services in Canada. Ottawa: Canadian Health Services Research Foundation.

Larson, J. (1999). The conceptualization of health. Medical Care Research and Review, $56(2), 123-136$. 
Lavis, J. (2002). Political elites and their influence on health-care reform in Canada (discussion paper no. 26, Catalogue No. CP32-79/26-2002E-IN). Ottawa: Commission on the Future of Health Care in Canada.

Lefebvre, S., Warren, C., Laclé, S., \& Sutcliffe, P. (2006). A framework to integrate social and economic determinants of health into the Ontario public health mandate: $A$ discussion paper. Sudbury, Ontario: Sudbury \& District Health Unit.

LeGrow, K. (2001). The family physicians role in a continuum of care framework for Newfoundland and Labrador: A framework for primary care renewal. St. John's: Government of Newfoundland and Labrador. Retrieved December 5, 2004, from http://www.gov.nf.ca/publicat/pcac/pcac.PDF

Lewis, S. (1995). Paradox, process and perception: the role of organizations in clinical practice guidelines development. Canadian Medical Association Journal, 153, 10731077.

Lewis, S. (Ed.). (2004). A thousand points of light? Moving forward on primary healthcare. Winnipeg: Author.

Lomas, J. (2000). Connecting research and policy. Canadian Journal of Policy Research, $140-144$.

Lomas J, Fooks C, Rice T, \& Labelle RJ. (Spring 1989). Paying physicians in Canada: minding our Ps and Qs. Health affairs, 80-102.

Longlett, S., Kruse, J., \& Wesley, R. (2001). Community-oriented primary care:

Historical perspective. Journal of the American Board of Family Practice, 14, 54-63.

Lorig, K. (2006). Action planning: A call to action. Journal of the American Board of Family Medicine, 19 (3), 324-235.

Mable A. L., \& Marriott, J. (2002). Sharing the learning - The health transition fund synthesis series: Primary health care. Ottawa: Health Canada.

Magnussen, L., Ehiri, J., \& Jolly, P. (2004). Comprehensive versus selective primary health care: Lessons for global health policy. Health Affairs, 23(3), 167-176.

Manitoba Ministry of Health (2002). Primary health care policy framework. Retrieved September 3, 2002, from http://www.gov.mb.ca/health/phc/framework.html

Mathews, M. \& Lockhart, A. (2003). Impact of alternative payment plans on the practice patterns for fee-for-service physicians in the Northwest Territories. Canadian Medial Association Journal, 8(2), 89-93.

Maxwell, J. (2002). Bringing values into health care reform. Canadian Medial Association Journal, 166 (12), 1543-1544. 
McColl, M., Shortt, S., O'Brien, P., Godwin, M., Rowe, K., \& Smith, K. (2006). Models for integrating rehabilitation and primary care. Kingston: Centre for Health Services and Policy Research, Queen's University.

McGowan, P. (2005). Patient self-management. Background paper to the new perspectives: International conference on patient self-management. Victoria: University of Victoria, Centre on Aging.

Mechanic, D. (2003). Who shall lead: Is there a future for population health? Journal of Health Politics, Policy and Law, 28 (2-3), 421-442.

Miller, R., \& Luft, H. (1997). Does managed care lead to better or worse quality of care? Health Affairs, 16(5), 7-25.

Millett, C. (2007). Impact of a pay-for-performance incentive on support for smoking cessation and on smoking prevalence among people with diabetes. Canadian Medical Association Journal, 1705-1711.

Minister's Implementation Committee. (1990). Health strategy for the nineties: managing better health. Halifax: Author.

Ministry of Health. (1987). Ontario Health Review Panel (J. Evans, Chairman). Toward a shared direction for health in Ontario. Toronto.

Ministry of Health and Long Term Care. (2007a). Guide to governance and accountability. Retrieved June 28, 2007, from

http://www.health.gov.on.ca/transformation/fht/fht guides.html

Ministry of Health and Long Term Care (2007b). Guide to business and operational plan development for FHTs. Retrieved June 28, 2007, from

http://www.health.gov.on.ca/transformation/fht/fht_guides.html

Ministry of Health and Long Term Care (2007c). Haliburton highlands family health team improving access to health care in Haliburton and surrounding areas. Retrieved October 10, 2007, from

http://www.health.gov.on.ca/english/media/news_releases/archives/nr 05/nr 093005 4.h $\underline{\mathrm{tml}}$

Ministry of Health and Long Term Care (2008). Progress on family health teams. Retrieved May 8, 2008, from http://www.health.gov.on.ca/transformation/fht/fht progress.html

Morgan, M., Zamora, N., \& Hindamarsh, M. (2007). An inconvenient truth: A sustainable healthcare system requires chronic disease prevention and management transformation. Healthcare Papers, 7(4), 6-23. 
Monrad, A. (1995). Incentives and financial methods. Health Policy. 34, 205-220.

Mowat, D. (1997). Primary care reform: Is it time for population-based funding? Canadian Medical Association Journal, 156; 143-144.

Mulligan, P. (2002). Capitation: the wrong direction for primary care reform. Canadian Family Physician, 43, 233-236.

National Forum on Health, Vol. II, Values Working Group. (1997). Canada health action: Building on the legacy: Synthesis reports and issues papers. Ottawa: Health Canada.

Naylor CD. (1986). Private practice, public payment: Canadian medicine and the politics of health insurance. Kingston and Montreal: McGill-Queen's University Press.

Nolte, J. (2005). Enhancing interdisciplinary collaboration in primary health care in Canada. Retrieved March 8, 2007, from http://www.eicp.ca/en/resources/pdfs/Enhancing-Interdisciplinary-Collaboration-inPrimary-Health-Care-in-Canada.pdf

Nurse Practitioners' Association of Ontario (2005). Strategies for successful integration of PHCNPs in family health teams: A discussion paper. Retrieved May 7, 2007, from http://www.npao.org/Uploads/public/Successful\%20Strategies $\% 20 \mathrm{NPs} \% 20$ and $\% 20 \mathrm{FHTs}$ $\% 20$ Aug05.pdf

Nurse Practitioners' Association of Ontario (March 2008). Position Statement: Team Based Bomuses is the correct way to go. Retrieved May 7, 2008, from http://www.npao.org/Uploads/members/Position $\% 20$ Statement $\% 20$ Team $\% 20$ Based $\% 20$ Bonuses $\% 20$ Correct $\% 20 \mathrm{Way} \% 20$ to $\% 20 \mathrm{Go} \% 20 \mathrm{Mar} \% 20$.pdf

Ontario Health Quality Council Report. 2008 Report on Ontario's Health System. Toronto: Ontario Health Quality Council.

Ontario Medical Association. (2007a). Policy on Primary Care. Toronto: Ontario Medical Association.

Ontario Medical Association. (2007b). Policy Paper - Interprofessional Care. Toronto: Ontario Medical Association.

Ostbye, T., Hunskarr, S. A new primary care rostering and capitation system in Norway: Lessons for Canada? Canadian Medical Association Journal, 156, 45-50.

Panitich, L. (1977). The Role and Nature of the Canadian State, in L. Panitch (Ed.), The Canadian State: Political Economy and Political Power (pp. 1-27). Toronto: University of Toronto Press. 
Patra, J., Popova, S., Rehn, J., Bondy, S., Flint, R., \& Giesbrecht, S. (2007). Economic cost of chronic disease in Canada 1995-2003. Toronto: Ontario Chronic Disease Prevention Alliance and the Ontario Public Health Association.

Patzer, K. (2006). A review of the trends and benefits of community engagement and local community governance in health care. Toronto: Association of Ontario Health Centres.

Pereira, A., \& Pearson, S. (2001). Patient attitudes toward physician financial incentives. Archives of Internal Medicine. 161:1313-1317.

Peterson, L., Woodward, L., Urech, T., Daw, C., \& Sookanan, S. (2006). Does pay-forperformance improve the quality of health care? Annals of Internal Medicine, 145 (4), $265-272$

Poland, B., Coburn, D., Robertson, A., \& Eakin, J. (1998). Wealth, equity and health care: A critique of a "population health" perspective on the determinants of health. Social Science and Medicine, 46 (7), 785-798.

Prada, G., Swettenham, J., Stonebridge, C., Schaafsma, M., Grimes, K., \& Thompson, L. (2005). Interdisciplinary primary health care: Finding the answers - a case study report. Retrieved March 8, 2007, from http://www.eicp.ca/en/toolkit/EICP-Case-Studies-Report-Final-Aug-14.pdf

Premier's Commission on Future Health Care for Albertans. (1989). The rainbow report: our vision for health. Edmonton: Ministry of Health.

Primary Health Care Transition Fund, Chronic Disease Prevention and Management. (1997). Retrieved May 7, 2007, from

http://www.hc-sc.gc.ca/hcs-sss/alt formats/hpb-dgps/pdf/prim/2006-chronic-chroniqueseng.pdf

Public Health Agency of Canada (2007). Physical Activity Guide for Older Adults.

Retrieved July 7, 2007, from

http://www.phac-aspc.gc.ca/pau-uap/paguide/older/index.html

Public Health Agency of Canada. (2006). Chronic Diseases in Canada Volume 27, No. 3. Retrieved May 17, 2007, from http://www.phac-aspc.gc.ca/publicat/cdic-mcc/273/index.html

Public Health Agency of Canada. Physical activity guide. Retrieved February 3, 2008, from http://www.phac-aspc.gc.ca/pauuap/paguide/gardening.html

Rachlis, M. (2004). Prescription for excellence. Toronto: Harper Collins. 
Rachlis, M. (2006). Challenges facing Canada's health care system. Speech Proceedings Vol. XXVIII, No 1. United States Indian American Chamber of Commerce third annual convention.

Raeburn, J..\& Rootman, I. (1999). The value of model programmes in mental health promotion and mental disorder prevention. International journal of mental health promotion, 1 (2), 18-19.

Raphael, D. (2001). Inequality is bad for our hearts: Why low income and social exclusion are major causes of heart disease in Canada. Toronto: North York Heart Health Network.

Registered Nurses Association of Ontario. (2007). Backgrounder on Ontario RNs in 2006. Retrieved January 4, 2007, from

http://www.rnao.org/Page.asp?PageID=122\&ContentID=1574\&SiteNodeID=137

Romanow, R. (2002). Building on values: The future of health care in Canada. Ottawa: Health Canada.

Royal Pharmaceutical Society of Great Britian and the British Medical Association (2000). Teamworking in primary healthcare: Realising shared aims in patient care. Retrieved August 8, 2007, from http://www.rpsgb.org.uk/pdfs/teamworking.pdf

Schlesinger, M. (2004) A broader vision for managed care, part 3: The scope and determinants of community benefits. Health Affairs, 23 (3), 210-221.

Schmittdiel, J., Shortell, S., Rundall, T., Bodenheimer, T., \& Selby, J. (2006). Effect of primary health care orientation on chronic care management. Annals of Family Medicine, $4(2), 117-123$.

Schoen, C., Osborn, R., Huynh, PT, Doty, M., Davis, K., Zapert, K., Peugh, J. (2004). Primary care and health system performance: Adults' experiences in five countries. Health Affairs, W4, 487-503.

Scott, G., \& Quigley, M. (2006). Ask an expert - A feature presented by Longwoods publishing in collaboration with a pool of leading experts in the design and management of healthcare organizations. Retrieved June 20,2008, from http://www.longwoods.com/ask_expert.php?ask_expert id =1\&cat $=120$

Solberg, L., Crain, AL., Sperl-Hillen, J., Hroscikoski, M., Engebretson, K., \& O'Conor, P. (2006). Care quality and implementation of the chronic care model: A quantitative study. Annals of Family Medicine, 4(4), 310-316.

Starfield, B. (1994). Is primary care essential? The Lancet, 344, 1129-1133. 
Starfield, B. (1998). Primary Care. Balancing health needs, services and technology. New York: Oxford University Press.

Starfield, B., Shi, L. (2002). Policy relevant determinants of health: an international perspective. Health Policy, 60, 201-218.

Starr, P. (1982). The social transformation of American medicine. New York: Basic Books.

Stonebridge, J. (2004). Primary health care: A framework that fits. Principles and framework literature review. Retrieved March 8, 2007, from http://www.eicp.ca/en/resources/pdfs/Barriers-and-Facilitators-to-EnhancingInterdisciplinary-Collaboration-in-Primary-Health-Care.pdf

Suschnigg, C. (2001). Reforming Ontario's primary health care system: One step forward, two steps back? International Journal of Health Services, 31(1), 91-1003.

Tanner, F. (1999). Community service centres of Ottawa-Carleton: A history. Retrieved January 4, 2008, from

http://www.coalitionottawa.ca/html/history.html

Tepper, J. (2004). The evolving role of Canada's family physicians, 1992-2001. Canadian Institute for Health Information.

The College of Family Physicians of Canada (2007). Primary care toolkit for family physicians. Remuneration methods. Retrieved October 15, 2007, from http://toolkit.cfpc.ca/en/remuneration/remuneration-methods.php

The Public Health Agency of Canada (2005). The integrated pan-Canadian healthy living strategy (ISBN 0-662-69384-1). Ottawa: Health Canada.

Wagner, E., Davis, C., Schaefer, J., Von Korff, M., \& Austin, B. (2002). A survey of leading chronic disease management programs: Are they consistent with the literature? Journal of Nursing Care Quality, 16(2), 67-80.

Wagner, E., Austin, B., \& Von Korff, M. (1996). Organizing care for patients with chronic illness. The Milbank Quarterly, 74, (4), 511-544.

Walsh, J., Swangard, D., Davis, T., \& McPhee, SJ. (1999). Exercise counseling by primary care physicians in the era of managed care. American Journal of Preventative Medicine, 16(4), 307-313.

Watson, D., \& Wong, S. (2005). Canadian policy context: Interdisciplinary collaboration in primary health care. Retrieved May 22, 2006, from http://www.eicp.ca/en/resources/pdfs/Canadian-Policy-Context-InterdisciplinaryCollaboration-in-Primary-Health-Care.pdf 
Way, D., Jones, L., Busing, N. (2000). Implementation strategies: Collaboration in primary care - family doctors \& nurse practitioners delivering shared care. Toronto: Ontario College of Family Physicians.

Willis, E. (1983). Medical dominance: The division of labour in Australian health care. Victoria.

Willis, E. (2006). Introduction: taking stock of medical dominance. The International Journal of Health Sociology, 15(5), 1-27.

Willison, K. (2007). Integrating self-care and chronic disease management through a community based research approach. Journal of Chinese Clinical Medicine, 2(6):336340 .

Wilner, S. (1986). Health promotion and disease prevention in HMOs. Health Affairs. 122-134.

World Health Organization. (1948). Preamble to the Constitution of the World Health Organization as adopted by the International Health Conference, New York.

World Health Organization. (1986). Ottawa Charter for Health Promotion. Ottawa: World Health Organization.

World Health Organization. (2005a). Action on the social determinants of health: Learning from previous experiences. Retrieved May 22, 2006, from http://www.who.int/social determinants/resources/action sd.pdf

World Health Organization. (2005b). Preventing chronic diseases: a vital investment. Retrieved May 22, 2006, from http://www.who.int/chp/chronic disease report/contents/en/index.html 